\title{
Plasma flow channels at the dawn/dusk polar cap boundaries: momentum transfer on old open field lines and the roles of IMF $B_{y}$ and conductivity gradients
}

\author{
P. E. Sandholt ${ }^{1}$ and C. J. Farrugia ${ }^{2}$ \\ ${ }^{1}$ Department of Physics, University of Oslo, Oslo, Norway \\ ${ }^{2}$ Space Science Center, University of New Hampshire, Durham, USA
}

Received: 30 October 2008 - Revised: 4 February 2009 - Accepted: 27 February 2009 - Published: 2 April 2009

\begin{abstract}
Using DMSP F13 data in conjunction with IMF data we investigate the newly discovered channels of enhanced $(1.5-3 \mathrm{~km} / \mathrm{s})$ antisunward convection occurring at the dawn (06:00-09:00 MLT) or dusk (15:00-18:00 MLT) flanks of the polar cap for different combinations of IMF $B_{y}$ polarity, hemisphere (NH/SH) and the dawn/dusk MLTs. Dawn-side cases where this flow channel appears occur for the following combinations: NH-dawn $/ B_{y}>0$ and $\mathrm{SH}-$ dawn $/ B_{y}<0$. The dusk-side cases are: NH-dusk $B_{y}<0$ and SH-dusk $/ B_{y}>0$. The flow channels are placed in the context of particle precipitation regimes/boundaries and ionospheric conductivity gradients. They are found to be threaded by "old open field lines" ("time since reconnection" > 10 min) characterized by polar rain precipitation. In the dawn-side cases $\left(\mathrm{NH}\right.$-dawn $/ B_{y}>0$ and $\mathrm{SH}$-dawn $\left./ B_{y}<0\right)$ and in a Parker spiral field, the polar rain contains the "solar wind strahl" component. The convection enhancement is attributed to the Pedersen current closure of Birkeland current sheets $(\mathrm{C} 1$ and $\mathrm{C} 2)$ in the polar cap (C1) and at the polar cap boundary (C2). The low ionospheric conductivity in the polar cap, particularly in the winter hemisphere, is compensated by an enhanced electric field driving the flow channel there. This is momentum transfer from the solar wind via dynamo action taking place in the combined current system of the high- and low-latitude boundary layers (HBL/LLBL). The conductivity gradient at the polar cap boundary contributes to establishing the convection channel and the associated enhancement of the dawn-dusk convection asymmetry extending beyond the dawn-dusk terminator during intervals of nonzero IMF $B_{y}$ component. The HBL/LLBL-ionosphere coupling via Birkeland currents $\mathrm{C} 1 / \mathrm{C} 2$ is a source of dawn-dusk convection asymmetry and Svalgaard-Mansurov effect which must
\end{abstract}

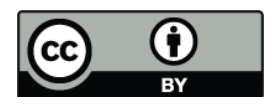

Correspondence to: P. E. Sandholt (p.e.sandholt@fys.uio.no) be added to the effect of magnetic tension acting on "newly open field lines".

Keywords. Magnetospheric physics (Magnetopause, cusp, and boundary layers; Polar cap phenomena; Solar windmagnetosphere interactions)

\section{Introduction}

In previous studies we aimed at a re-vitalization of a long tradition in the field of solar wind-magnetosphere-ionosphere coupling to which little attention has been directed in recent years. This is the question of momentum transfer "on old open magnetic field lines" connected to dynamo action taking place in the high-latitude boundary layer (HBL), tailward of the cusp (Cowley, 1981; Stern, 1984; Siscoe et al., 1991, 2000; Taguchi et al., 1993). We emphasized the role of momentum transfer from the HBL contributing to the dawn-dusk ionospheric convection asymmetry during intervals of nonzero IMF $B_{y}$ component (Sandholt et al., 2006b). This is a controversial issue in view of the widespread view that momentum transfer is restricted to "newly open field lines" (Lockwood et al., 1990). In the latter framework the IMF $B_{y}$-related dawn-dusk asymmetry in polar cap convection is explained exclusively in terms of magnetic field line tension on "newly open field lines" (Jørgensen et al., 1972; Gosling et al., 1990).

In our recent studies we suggested an additional source of the convection asymmetry which is observed to extend beyond the dawn - dusk terminator. This is the newly discovered channels of enhanced antisunward convection observed on the morning (evening) side of the polar cap during positive (negative) IMF $B_{y}$ condition when we refer to Northern Hemisphere cases (Sandholt et al., 2004; Farrugia et al., 2004a; Sandholt et al., 2006b; Sandholt and Farrugia,

Published by Copernicus Publications on behalf of the European Geosciences Union. 
2007a,b; Lund et al., 2008). On the basis of magnetic field and ion drift data obtained during traversals of the polar cap by satellite DMSP F13 we suggested that these flow channels are driven by the ionospheric Pedersen current closure of the HCC-LCC Birkeland current system identified by Taguchi et al. (1993), Birkeland currents which flow poleward of the traditional Regions 1 and 2 (R1/R2) currents. We also suggested that ionospheric conductivity plays an important role in establishing the strong ionospheric electric field which drive the flow channels at the polar cap boundary (Sandholt et al., 2006b).

The noonward extension of the flow channels observed on the mid-morning ( $\sim 09: 00$ MLT) or postnoon ( $15: 00$ MLT) sides of the polar cap (depending on the $B_{y}$ polarity) was found to be associated with the high-latitude stage of poleward moving auroral forms (PMAFs/prenoon $/ B_{y}>0$; PMAFs/postnoon $\left./ B_{y}<0\right)$, within the regime of mantle precipitation (Sandholt and Farrugia, 2007a).

In these previous studies we distinguished between two categories of flow channels during intervals with a significant IMF $B_{y}$ component, i.e., those located on "newly open" (called hereunder FC 1) and those associated with "old open field lines" (FC 2). By the term "old open" field lines we mean magnetic field lines that have been reconnected in the past, i.e., those whose "time since reconnection" (Lockwood et al., 1993) is $>10 \mathrm{~min}$. By this time field lines opened at the dayside low latitudes have been convected beyond the geomagnetic field bifurcation and downstream of the cusp (Smith, 1994). They would then have their "feet" in mantle or polar rain precipitation. This is a terminology and definition we have used in early papers in 2003, 2004.

In this study we shall direct attention exclusively on FC 2, the topic of momentum transfer on "old open field lines" and its contribution to the dawn-dusk convection asymmetry. Emphasis will be placed on the spatial structure (in latitude and longitude) of the flow channels and the relationship to particle precipitation regimes and boundaries. The roles played by ionospheric conductivity and conductivity gradients are particularly important. The latter may indicate a seasonal dependence which we will investigate. We shall therefore demonstrate case examples of ion drift and precipitation data obtained during dawn-dusk passes of spacecraft DMSP F13 in both the winter and summer hemispheres. The DMSP observations presented here are a continuation/extension of the preliminary results reported in Sandholt et al. (2004) and in Sandholt et al. (2006b).

We shall apply data from selected intervals with stable IMF conditions allowing multiple cross polar cap passages of F13 in both hemispheres under the same IMF conditions. Thus, in addition to normal solar wind intervals, we shall also use interplanetary magnetic cloud intervals, which are characterized by strong and stable IMF $B_{y}$ conditions of long duration (Lepping et al., 2003) to probe this issue. We shall distinguish between the following categories of events, sorted by IMF $B_{y}$ polarity, hemisphere (north and south), and sun- light (conductivity) conditions in the ionosphere of the different hemispheres: (i) $\mathrm{NH}$-dawn $/ B_{y}>0$, (ii) SH-dusk $/ B_{y}>0$, (iii) NH-dusk $/ B_{y}<0$, and (iv) $\mathrm{SH}$-dawn $/ B_{y}<0$. According to Lu et al. (1994) the plasma convection in the cases (i) and (ii) and the cases (iii) and (iv) are generally mirror images of each other. In this paper we shall examine this issue further.

A schematic illustration of our model of the electric current systems related to flow channel FC 2 for the different categories mentioned above and the associated IMF - magnetosphere ("old open" field lines; OOFL) interconnection topologies are given in Figs. 1a and b. The current system consists of the following parts: (i) ionospheric Pedersen current, (ii) Birkeland currents in latitudinally separate sheets of opposite current direction (R1/C2 and C1), (iii) the LLBL current $\left(\boldsymbol{J}_{\mathrm{LLBL}}\right)$ and (iv) the magnetopause current $\left(\boldsymbol{J}_{\mathrm{MP}}\right)$. The origin of the $\mathrm{C} 1$ Birkeland current is due to the nonzero divergence of the magnetopause current $\left(\boldsymbol{J}_{\mathrm{MP}}\right)$ appearing in relation to the indicated dawn-dusk asymmetry of the IMFmagnetosphere interconnection topology and the associated electric field coupling (see e.g. Cowley, 1981). Our C1/C2 currents correspond to the "extra R0"/"extra R1" currents of Watanabe et al. (1996). In the Watanabe et al. (1996) description the "extra R0 current", generated in the tail magnetopause, is connected to the "extra R1 current" generated in the downstreamside LLBL (see their Fig. 10b).

In this paper we shall focus on the magnetosphereionosphere coupling in the 06:00-09:00 and 15:0018:00 MLT sectors where the R1 current is observed to be bifurcated during intervals of nonzero $B_{y}$ component (Watanabe et al., 1996) (see their Fig. 7). The two latitudinally separate branches of Birkeland current flowing in the same direction (in or out of the ionosphere) in their model are those we refer to as C2 (northernmost branch) and R1 (see Discussion). Applying the multi-layered boundary model of Sonnerup and Siebert (2003) the R1 and C2 currents map to the inner (closed) and outer (open) parts of the LLBL, respectively. The latter distinction is illustrated in the schematic Fig. 1. Thus, the magnetospheric sources of the $\mathrm{C} 2$ and $\mathrm{R} 1$ currents are the nonzero divergence of the cross-field current flowing across the LLBL $\left(J_{\text {LLBL }}\right)$, in its outer and inner parts, respectively.

Previous studies by other researchers relating to our investigation of the role of ionospheric conductance in plasma convection have been reported by Crooker and Rich (1993), Tanaka (2001), and Ruohoniemi and Greenwald (2005). Crooker and Rich (1993) found a winter-summer hemisphere asymmetry which they interpreted in terms of the effects of dipole tilt (lobe cell in summer). More relevant to our study is their finding that the dusk cell dominates the dawn cell in winter, consistent with the presence of a day-night conductivity gradient.

Weimer (1995) found that although "the ratio between the potentials in the dawn and dusk cells (dawn-dusk asymmetry) is influenced by the season or dipole tilt angle, it is interesting that the peak polar cap potential drop is about the same 

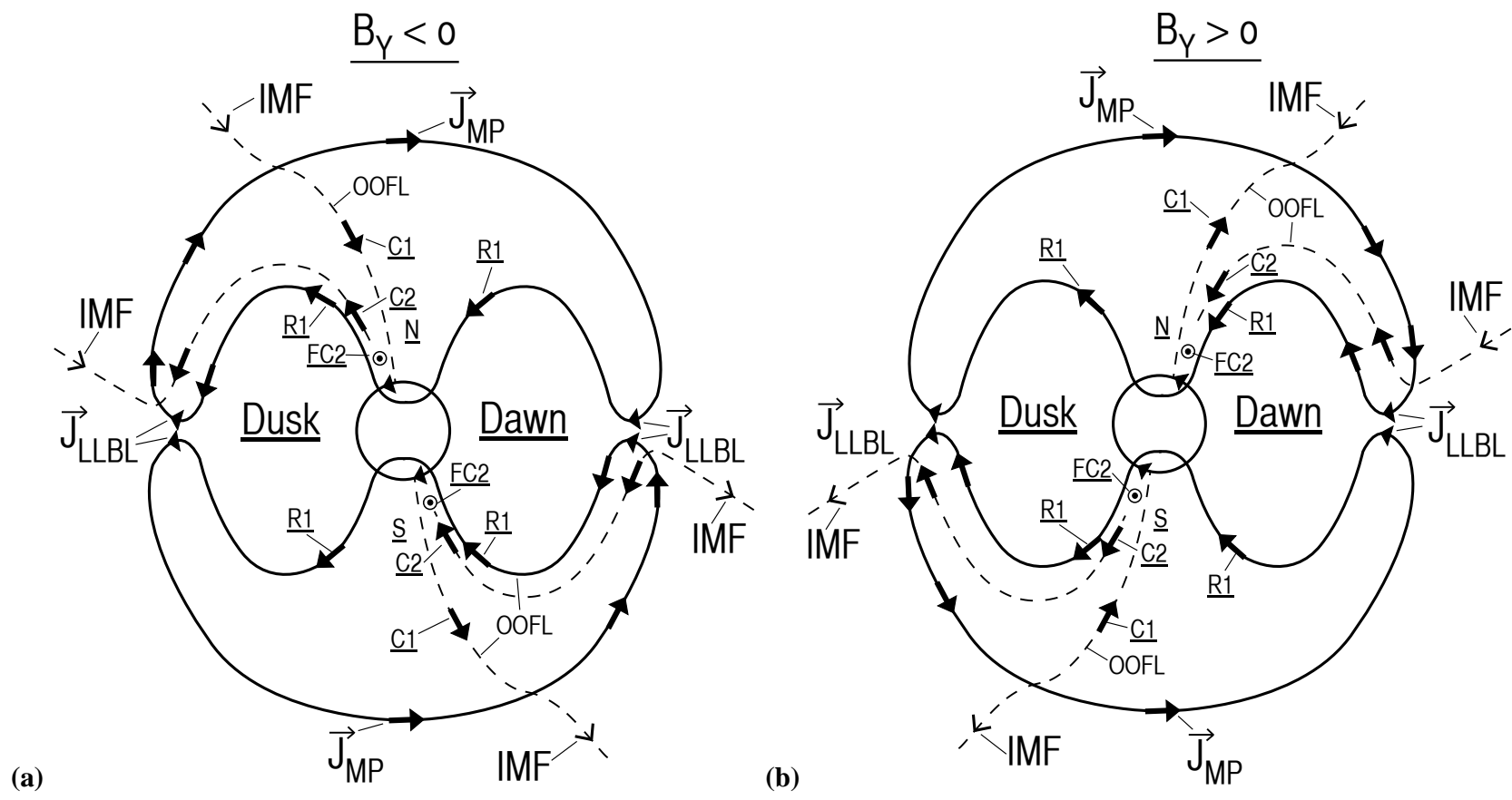

Fig. 1. Schematic illustration of current systems related to flow channel FC 2. Panel (a) shows event categories NH-dusk/ $B_{y}<0$ (top left) and SH-dawn $/ B_{y}<0$ (bottom right). Panel (b) shows the types $\mathrm{NH}$-dawn/ $B_{y}>0$ (top right) and SH-dusk/ $B_{y}>0$ (bottom left). The corresponding IMF-magnetosphere interconnection topologies are marked by an old open field line (OOFL). The perspective is from the magnetotail towards the Sun. (North is up and Dusk is to the left).

at summer, winter, and equinox." He notes that the "it may be necessary to include the effects of ionospheric conductivity gradients, which may cause a rotation of the potentials imposed by the solar wind".

Tanaka (2001) argued that the ionospheric convection pattern should be considered the synthesized effect of magnetospheric and ionospheric factors. Specifically, the projection of plasma convection from the magnetosphere needs to be balanced with the requirement of field-aligned current closure in the ionosphere. Ionospheric conductivity gradients were found to have a significant effect on convection in the region of the Harang discontinuity. This effect has been documented previously on small/medium scales by the rocket and radar observations reported by Marklund (1984). In their model of the "evening anticorrelation arcs" the reduced precipitation-induced conductivity just equatorward of the arcs is compensated by an enhanced electric field. The low ionospheric conductivity leads to an enhanced E-field in order to drive the Pedersen current closing the system of upward and downward directed Birkeland currents (Smiddy et al., 1980) oriented in the same way as the Region 1 and 2 currents. Karlsson and Marklund (1996) documented the presence of small-scale $(1-5 \mathrm{~km})$, intense $(>200 \mathrm{mV} / \mathrm{m}$ at $1500 \mathrm{~km}$ altitude) electric fields in east-west aligned, lowconductivity bands devoid of auroral emission, primarily on the nightside. The majority of the events were found to be associated with low ambient ionospheric conductivities.
Ruohoniemi and Greenwald (2005) found that the influence of season on convection depends on the IMF, especially the sign of $B_{y}$. They speculated that variability in the ionospheric conductivity has a greater effect on M-I coupling under $B_{y}$ negative conditions.

In this study we document the presence of a strong (1.5$3 \mathrm{~km} / \mathrm{s}$ ) convection channel during IMF $B_{y}<0$ conditions located (i) poleward of the "evening anti-correlation arc" in the Northern Hemisphere winter (21 January 2001; NHdusk $\left./ B_{y}<0\right)$ and (ii) at the dawnside polar cap boundary in the Southern Hemisphere winter (20 August 1998; SHdawn $\left./ B_{y}<0\right)$.

A similar effect is observed under IMF $B_{y}>0$ conditions (i) at dawn in the Northern Hemisphere winter (12 December 1999; NH-dawn $/ B_{y}>0$ ) and at dusk in the Southern Hemisphere during spring (17 April 1999; SH-dusk/ $B_{y}>0$ ). We thus conclude that the effect is present for both $B_{y}$ polarities. The convection channel is present in the dawn (06:0009:00 MLT) or dusk (15:00-18:00 MLT) sides of the polar cap depending on the combination of $B_{y}$ polarity and hemisphere (N/S). It is accompanied by polar rain electron precipitations (with or without the "solar wind strahl" component), i.e., it is threaded by "old open field lines" which means that they were reconnected some time (>10 min) in the past. The "strahl" is the closely field-aligned electron component of the solar wind halo population which is observed to have direct access to the magnetospheric lobe in the hemisphere where 


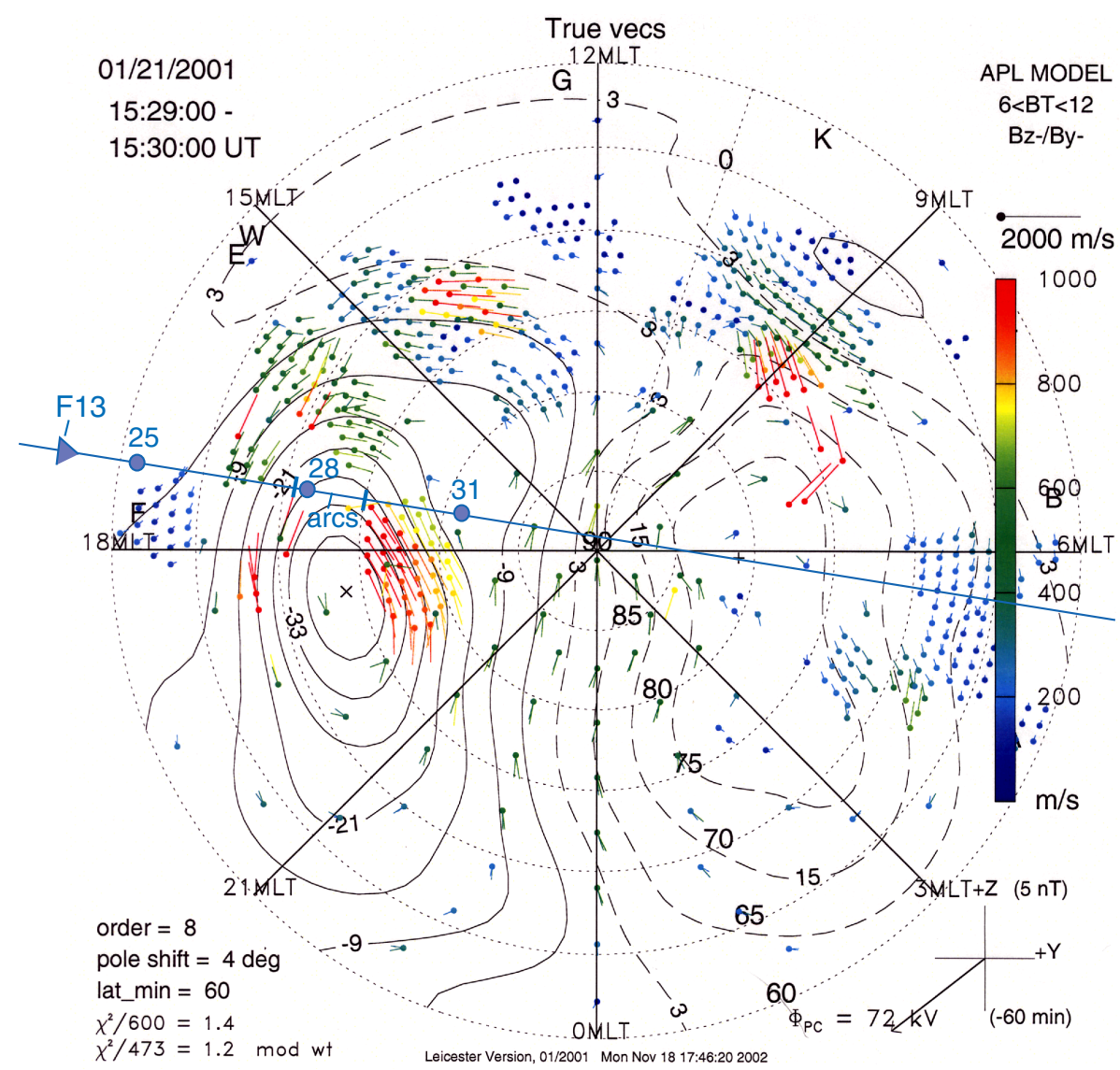

Fig. 2. Observations of flow channel FC 2 by SuperDARN radars during the NH-dusk/ $B_{y}<0$ case at $15: 30$ UT on 21 January 2001. The coordinate system is MLAT/MLT. The track of spacecraft DMSP F 13 during a crossing of duskside arcs (15:28-15:29 UT; 70-74 MLAT) and flow channel FC 2 (15:29-15:31 UT; 74-80 MLAT/17:00-19:00 MLT) on 21 January 2001 is shown by the blue line. From Sandholt et al. (2006b).

particle entry is favoured by the IMF $B_{x}$ polarity (NH for away sector, $B_{x}<0$, and $\mathrm{SH}$ for a toward sector, $B_{x}>0$ ), as documented by Fairfield and Scudder (1985).

A convection phenomenon similar to that discussed in this paper, called "rapid plasma flows" (RPFs), has been previously documented in the evening/midnight (21:0001:00 MLT) sector and attributed to M-I coupling along field lines threaded by plasma sheet boundary layer (PSBL) plasma (Burke et al., 1994). We note that these RPFs were not discussed in relation to IMF $B_{y}$. Kullen et al. (2008) pointed out that the possible contribution of rapid plasma flows to the large-scale plasma convection has not yet been studied observationally. According to Kullen et al. (2008) the relative contribution of the most intense $\mathbf{E}$-field peaks (flows) near auroral arcs to the general plasma flux is limited due to the extremely narrow structure.

This paper is organized as follows. First we reproduce a combined ground-satellite observation of the ionospheric FC 2 flow channel for the case NH-dusk/ $B_{y}<0$ from Sandholt and Farrugia (2007a). Then we will check the different FC 2 variants presented in Fig. 1 by reporting new data ex- amples in five different cases (1 October 2002, 20 August 1998; 12 December 1999; 21 January 2001; and 10 January 1997). This is followed by a summary of the observations, where we identify the characteristics of the different variants (categories) of the flow channel as sorted by IMF $B_{y}$ polarity, hemisphere, and dawn-dusk side of the polar cap. The electrodynamics of the arcs bordering the flow channels on their equatorward side and the implications in terms of magnetosphere-ionosphere coupling are treated in the Discussion section. We end by summarizing the central results of the investigation.

\section{Data description}

\subsection{Ground-satellite observations of FC 2: category NH-dusk $/ B_{y}<0$}

As an introduction to this study we reproduce from Sandholt and Farrugia (2007a) two figures illustrating the combined ground and satellite observations of flow channel FC 2 . 
F13

$21 \operatorname{Jan} 2001$

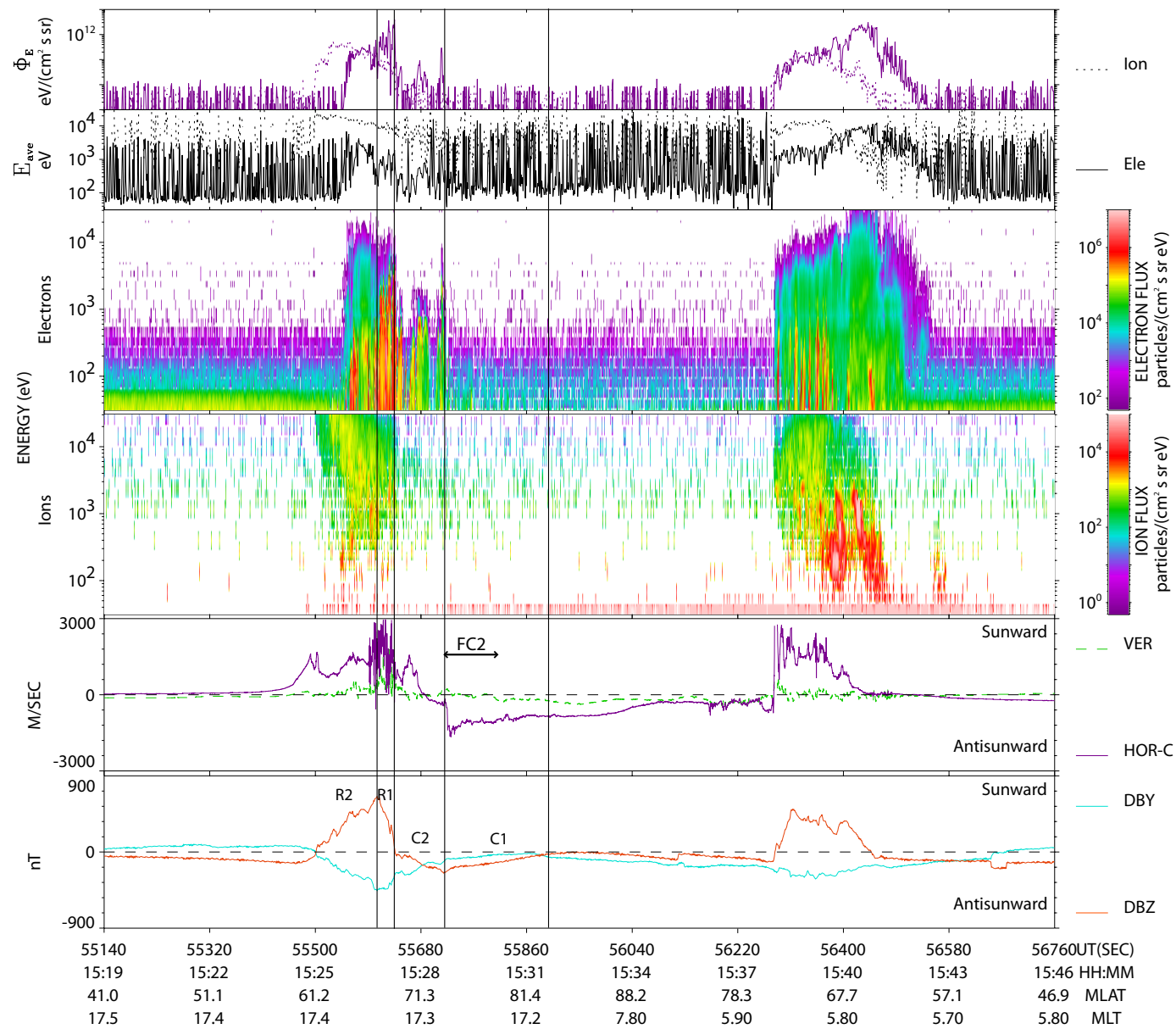

Fig. 3. DMSP F13 data from the NH-dusk/ $B_{y}<0$ case during the interval 15:19-15:46 UT on 21 January 2001. Panels from top to bottom shows (i) energy fluxes of precipitating ions and electrons, (ii) average energy (ions and electrons), (iii-iv) electron and ion spectrograms (differential energy flux), (v) cross-track horizontal ion drift, and magnetic deflection components $B_{z}$ (east-west) and $B_{y}$ (along track). Different latitude regimes of particle precipitation and Birkeland current (C1-C2-R1-R2) are marked by vertical guidelines. Flow channel FC 2 is indicated in the ion drift panel. From Sandholt et al. (2006b).

Thus, this case shows two independent measurements of flow channel FC 2. Figure 2 shows FC 2 within $74-80^{\circ}$ MLAT along the dusk meridian at 15:30 UT on 21 January 2001 as observed by SuperDARN radars (Greenwald et al., 1995). The channel of antisunward flow (FC 2) indicated by red arrows (74-80 MLAT/17:00-19:00 MLT) is located immediately poleward of dusk-side arcs (70-74 ${ }^{\circ}$ MLAT) which are also marked in the figure. Spacecraft DMSP F13 crossed this convection channel during the interval 15:29-15:31 UT. The F13 track is marked in the figure. The DMSP F13 data are shown below.

Figure 3 shows data from the F13 dusk-dawn pass at around 15:30 UT on 21 January 2001 (Fig. 2). This is an illustration of flow channel FC 2 in relation to the C1-C2-R1$\mathrm{R} 2$ Birkeland currents for the variant $\mathrm{NH}$-dusk/ $B_{y}<0$ (see Fig. 1a). In this case spacecraft DMSP F13 crossed the Northern Hemisphere polar cap from the dusk side at $71.5^{\circ}$
MLAT/17.3 MLT to the dawn side at $78^{\circ}$ MLAT/5.9 MLT. We shall focus on panels (iii); electron precipitation: differential energy flux, (v); cross-track ion drift, and (vi); eastward magnetic deflection $\left(B_{z}\right)$ /Birkeland current (red curve). Different latitude regimes on the dusk side sorted by particle precipitation, ion drift and Birkeland currents characteristics may be identified. At increasing duskside MLATs we notice the following regimes: (i) Energetic, diffuse particle precipitation/R2 Birkeland current. (ii) BPS-type precipitation/R1 Birkeland current. (iii) Evening anticorrelation arcs (EAAs) - C2 Birkeland current. (iv) Polar rain precipitation - flow channel FC 2 - C1 Birkeland current (directed into the ionosphere).

Flow channel FC 2 is characterized by (i) an abrupt enhancement of the antisunward ion drift at the poleward boundary of the EAAs and (ii) a more gradual decrease with increasing distance from the arc on the polar cap side. C2 


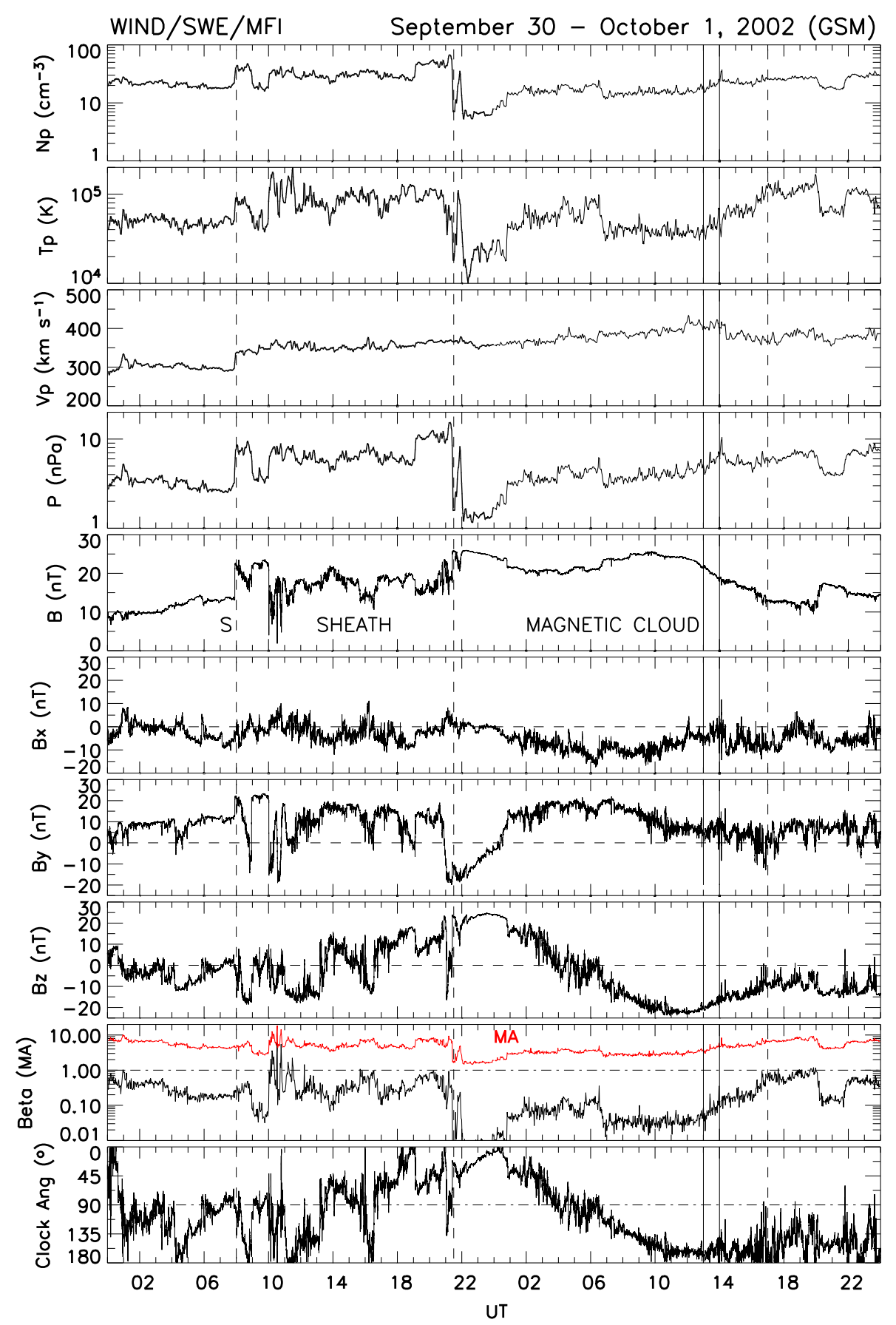

Fig. 4. Solar wind plasma and IMF observations from spacecraft Wind during the interval 00:00 UT (30 September)-24:00 UT (1 October), 2002. Panels from top to bottom show (i) proton density, (ii) proton temperature, (iii) bulk speed, (iv) solar wind dynamic pressure, (v) IMF total field, (vi-viii) the field components $B_{x}, B_{y}, B_{z}$, (ix) Alfvén-Mach number (MA; red) and proton beta, and (x) the IMF clock angle $(\theta)$. The shock $(\mathrm{S})$, sheath, and the cloud proper are marked by dashed vertical guidelines. Interval in focus here (13:00-14:00 UT) is also marked.

may be considered the poleward part of the R1 current. The $\mathrm{C} 2$ and R1 parts are distinguished by different current intensity (gradient in magnetic deflection) and particle precipitation characteristics. The $\mathrm{C} 2$ arcs show the properties of flow shear arcs (FSAs) and inverted - V arcs: (i) depressed ion $\mathrm{drift} / \mathbf{E}$-field within the $\operatorname{arc}(\mathrm{s})$ and (ii) enhanced ion drift/Efield of opposite polarity on either side. 


\subsection{Case 1: 1 October 2002 (IP magnetic cloud); $B_{y}>0$ : NH-dawn}

Figure 4 shows solar wind and IMF data from spacecraft Wind during the interval 00:00 UT (30 September)-24:00 UT (1 October), 2002. At 12:00 UT Wind was located at (87, $37,5) R_{E}$. This figure shows the interplanetary (IP) conditions surrounding Earth during the passage of an IP magnetic cloud (Burlaga et al., 1981). The features marked by the vertical guidelines are the shock $(\mathrm{S})$, the following sheath, and the magnetic cloud proper (21:30 UT, 30 September17:00 UT, 1 October 2002). The latter is characterized by a strong field, a low proton beta, and a slow rotation of the field from strongly north $\left(B_{z}=25 \mathrm{nT}\right.$; clock angle $\left.(\theta)=0^{\circ}\right)$ at 00.30 UT to strongly south $\left(B_{z}=-20 \mathrm{nT}\right.$; clock angle $\left.=160^{\circ}\right)$ at 12:00 UT on 1 October. So, this is a north-south (NS) type of cloud (see e.g. Lepping et al., 2003). The bulk speed is near $400 \mathrm{~km} / \mathrm{s}$ making this a slow magnetic cloud. We shall be particularly concerned with conditions prevailing during 13:00-14:00 UT on 1 October when $B_{z}=-20$ to $-15 \mathrm{nT} ; B_{y}=5-10 \mathrm{nT}$; clock angle $\theta \sim 155^{\circ} ; B_{x}=-5$ to 0 (see solid vertical guidelines).

Figure 5 shows two selected DMSP F13 tracks across the polar cap in the Northern Hemisphere $(\mathrm{NH})$. The coordinate system is MLAT/MLT. In this $\mathrm{NH} / B_{y}>0$ case we shall focus on the polar cap boundary on the prenoon/dawn side (see Fig. 1b). This is a case with sunlit polar cap ionosphere along the track. The intervals in focus are 08:51-08:57 and 13:5914:05 UT. Flow channel FC 2 (hatched arrow), convection reversal (CR), precipitation (CPS, BPS, mantle (MA), polar rain (P.RAIN)) and Birkeland current regimes (R2, R1, C2, C1) are marked along the track. We notice that flow channel FC 2 is located in the regimes of mantle (MA) and polar rain (P.RAIN) precipitations along the $\sim 09: 00$ and 06:30 MLT meridians, respectively. At these two times the Earth was embedded in the IP cloud characterized by a strong field (18$25 \mathrm{nT})$ which was directed south-east: $B_{z}=-15(-17) \mathrm{nT}$; $B_{y}=15(5) \mathrm{nT} ; \theta=135\left(155^{\circ}\right)$. The F13 data obtained at these times will now be shown.

Figure 6 shows DMSP F13 data obtained during a crossing of the polar cap in the Northern Hemisphere during 08:3609:06 UT (see Fig. 5). Panels from top to bottom show: (i) electron precipitation flux versus energy, (ii) ion precipitation flux, (iii) ion density, (iv) horizontal (normal to track; violet) and vertical (green) ion drifts, and (v) magnetic deflection components $B_{x}, B_{y}$ and $B_{z}$ (green; horizontal across track).

We distinguish between the following regimes marked in the figure: (1) postnoon polar cap arcs associated with flow shear, i.e., flow shear arcs (Sandholt et al., 2006a), (2) polar rain and standard $B_{y}$ - related dawn-dusk asymmetrical polar cap convection, (3) C1-type Birkeland current, mantle precipitation and enhanced antisunward convection, (4) C2-type Birkeland current, mantle/LLBL precipitation, and enhanced $(1.5 \mathrm{~km} / \mathrm{s})$ antisunward convection (FC 2), (5) R1 Birkeland current, LLBL/BPS - type precipitation in the vicinity of the

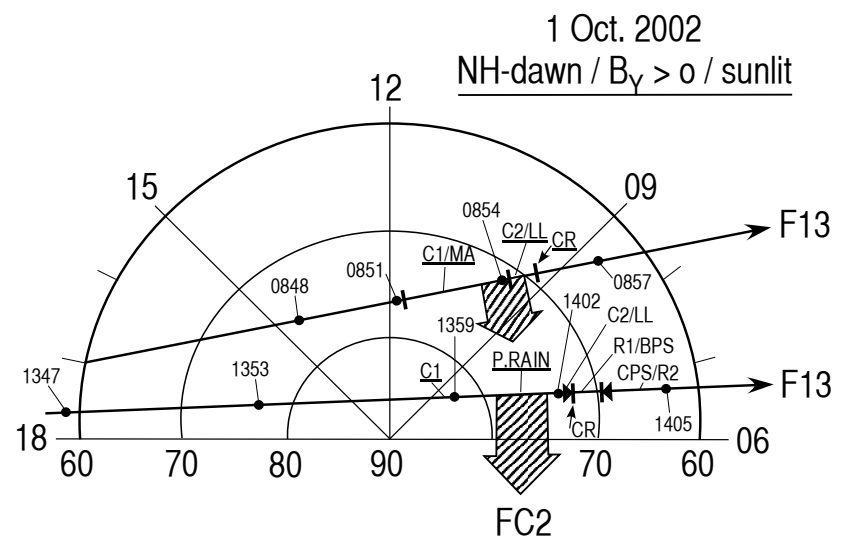

Fig. 5. DMSP F13 tracks across the polar cap in the Northern Hemisphere (NH) shown in MLT/MLAT coordinates during the intervals 08:48-08:57 and 13:47-14:05 UT. The event category is NHdawn $/ B_{y}>0$ (sunlit). Convection channel FC 2 is marked by the broad hatched arrow. Particle precipitation (CPS, MA, P.RAIN) and Birkeland current regimes (R2 (CPS), R1 (BPS), C2 (MA/P.RAIN), C1 (MA/P.RAIN)) are marked along the track, on the dawn (right) side.

convection reversal, (6) R2 Birkeland current, CPS precipitation and slow sunward convection.

Birkeland currents $\mathrm{C} 1$ and $\mathrm{C} 2$ (regimes 3 and 4 ) are identified from the magnetic deflection $\left(B_{z}\right)$ and the ion drift $\left(V_{\text {HORZ }}\right)$ trace in the fourth and bottom panels. These currents are flowing in the regime of mantle precipitation and antisunward convection $\left(V_{\mathrm{HORZ}}>1 \mathrm{~km} / \mathrm{s}\right)$. Birkeland current $\mathrm{R} 1$ (regime 5) flows in a latitudinally narrow regime which is characterized by LLBL/BPS type precipitation and a large ion drift gradient in the vicinity of the convection reversal. Flow channel FC $2(1.5-2.0 \mathrm{~km} / \mathrm{s}$ antisunward convection) is identified within $\sim 70-73^{\circ}$ MLAT.

Figure 7 shows another representative example of the DMSP F13 data obtained during a dawn-to-dusk crossing of the polar cap in the Northern Hemisphere during 13:4114:11 UT (see Fig. 5). This time the track is directed almost along the 06:30 MLT meridian.

Vertical guidelines are introduced to mark latitude regimes with different precipitation, ion drift, and Birkeland current characteristics. We note the following latitude regimes of Birkeland current, precipitation and convection, marked 15 in the bottom panel: (1) $\mathrm{C} 1$ current and polar rain with antisunward convection, (2) polar rain and flow channel FC 2, (3) C2 current and LLBL with antisunward convection/convection gradient, (4) R1 current and LLBL with sunward convection, and (5) R2 current and CPS (sunward convection). The antisunward (cross-track component) convection speed in FC 2 is $1.7 \mathrm{~km} / \mathrm{s}$. The background convection in the central polar cap (regime 1) is $0.8-1.0 \mathrm{~km} / \mathrm{s}$. The convection reversal is located at the boundary between regimes 3 and 4 (Note the bifurcation in the horizontal (violet) velocity component at 14:02 UT.) This means that the C2 current 


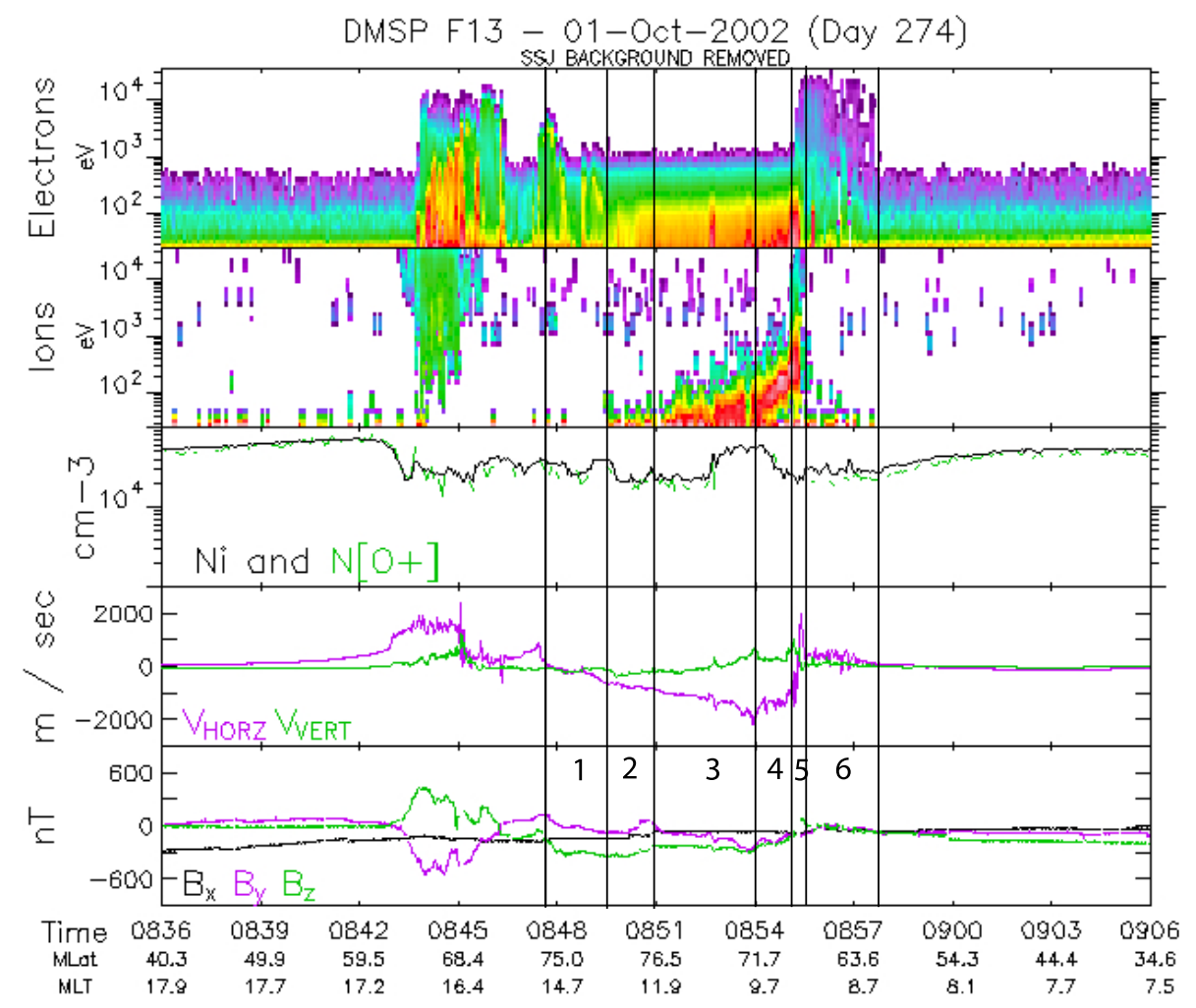

Fig. 6. Northern Hemisphere DMSP F13 data for the interval 08:36-09:06 UT. Cross track ion drift (panel 4) is shown in the context of particle precipitation (panels 1 and 2) and Birkeland current regimes ( $B_{z}$ trace in the bottom panel). Polar cap arcs (regime 1), polar rain precipitation (2), and Birkeland current regimes C1 (3), C2 (4), R1 (5), and R2 (6) are delimited by vertical guidelines. Event category: NH-dawn $/ B_{y}>0$ (sunlit).

is flowing along antisunward convecting field lines while the $\mathrm{R} 1$ current is in the regime of sunward convection. Thus, the FC 2 and the related $\mathrm{C} 1-\mathrm{C} 2$ Birkeland currents shown schematically in the upper right section of Fig. 1b) were identified.

\subsection{Case 2: 20 August 1998 (IP magnetic cloud); $B_{y}<0$ : SH-dawn and NH-dusk}

Figure 8 shows solar wind and IMF data obtained from spacecraft Wind during the interval 16:00 UT (19 August)12:00 UT (21 August). Wind was located at $(63.8,-36.2$, -4.0) $R_{E}$ (GSE coordinates) at 12:00 UT, 20 August, in the middle of the interval we study in detail. IP conditions surrounding Earth again correspond to the passage of an IP magnetic cloud (Burlaga et al., 1981). The cloud interval lies between the times indicated by the second and last vertical guidelines. The $B_{z}$ component executes a slow southto-north rotation, so that this is a (S-N) cloud. Preceding the cloud are the driven shock (first vertical guideline) and the sheath region. We shall focus on the period 09:0018:00 UT, 20 August in the leading phase of the magnetic cloud, marked by vertical guidelines. This interval is characterized by very stable IMF parameters having the follow- ing average values: $B_{x}=5 \mathrm{nT} ; B_{y}=-10 \mathrm{nT}$, the clock angle in the GSM Y-Z plane $=135^{\circ}$. The solar wind velocity is $350 \mathrm{~km} / \mathrm{s}$. The solar wind density and dynamic pressure are $\sim 8-10 \mathrm{~cm}^{-3}$ and $1-2 \mathrm{nPa}$, respectively. We note that although this is a solar wind transient, the relative polarities of $B_{x}$ and $B_{y}$ are the same as that of the Parker spiral in a toward sector.

Figure 9 shows three selected DMSP F13 tracks across the southern polar cap ( $\mathrm{SH})$. The coordinate system is MLAT/MLT. In this $\mathrm{SH} / B_{y}<0$ case we shall focus on the polar cap boundary on the dawn side (Fig. 1a). This is a case with dark polar cap ionosphere along the spacecraft track. The intervals in focus are: (i) 16:02-16:14 UT, (ii) 12:41-12:53 UT, and (iii) 11:00-11:12 UT. Flow channel FC 2 (hatched arrows), convection reversal (CR), precipitation (CPS, BPS, polar rain) and Birkeland current regimes (R2, R1, C2, C1) are marked along the tracks. Flow channel FC 2 is located in the regime of polar rain precipitation (P.RAIN). The equatorward boundaries of polar rain precipitation, Birkeland current $\mathrm{C} 1$, and FC 2 are the same. The corresponding data examples will now be shown.

Figure 10 shows a representative example of the DMSP F13 data obtained during a dawn-to-dusk crossing of the polar cap in the Southern Hemisphere (see Fig. 9). The event 


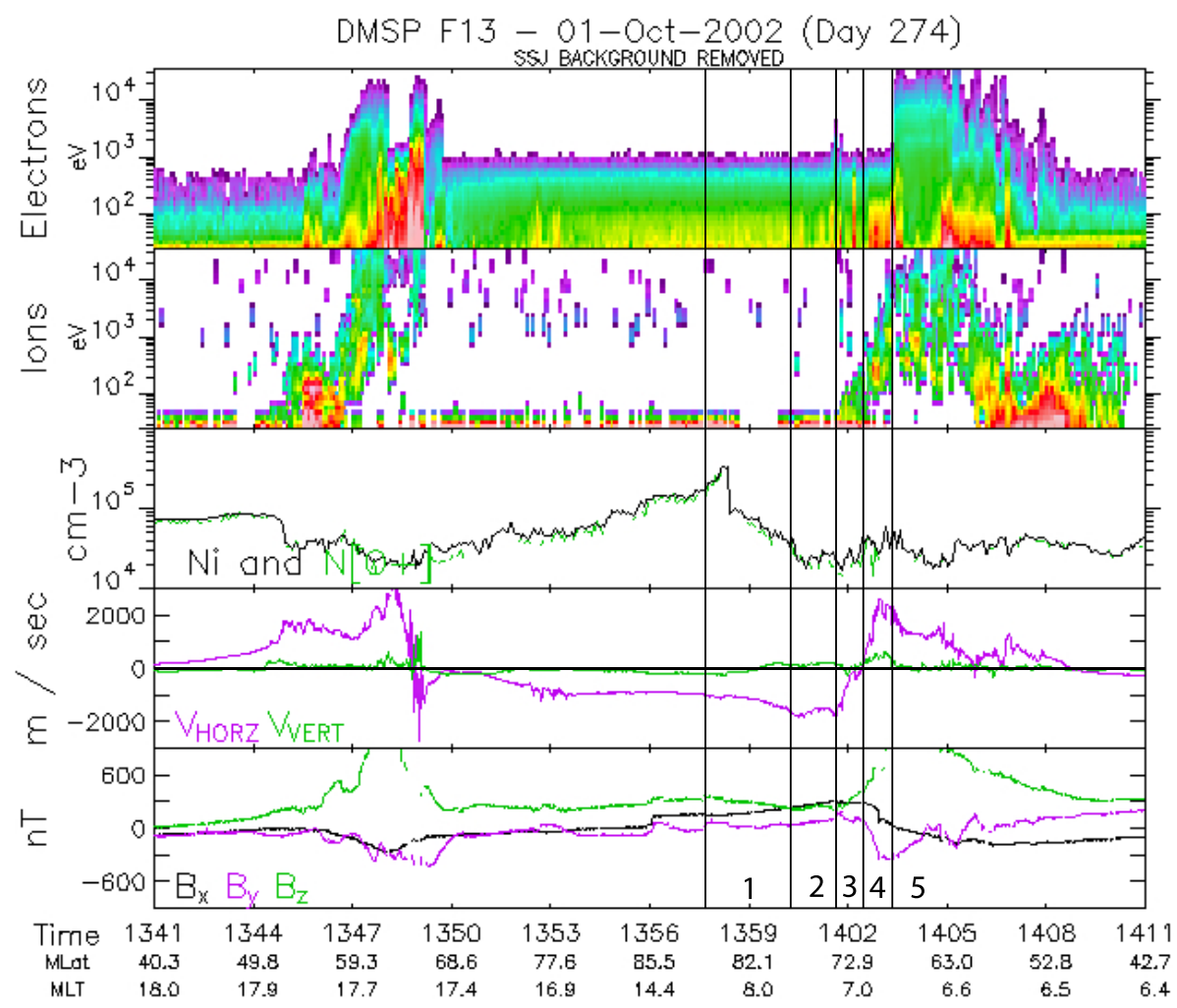

Fig. 7. Northern Hemisphere DMSP F13 data for the interval 13:41-14:11 UT. Cross track ion drift (panel 4) is shown in the context of particle precipitation (panels 1 and 2 ) and Birkeland current regimes ( $B_{z}$ trace in bottom panel). Precipitation/Birkeland current/convection regimes marked by vertical guidelines are: (1): P.RAIN and C1; (2): P.RAIN and flow channel FC 2; (3): C2 current, (4): R1 current; and (5): R2 current. Event category: NH-dawn $/ B_{y}>0$ (sunlit). Same format as in Fig. 6.

category is $\mathrm{SH}$-dawn $/ B_{y}<0$ (dark ionosphere). The format is the same as in Fig. 6. Vertical guidelines are introduced to mark a channel of very enhanced antisunward flow in the polar cap (FC 2), with ion speeds in excess of $2 \mathrm{~km} / \mathrm{s}$ (panel four). This is a case with a clear dawn-dusk asymmetry of the polar cap convection with the largest flow speeds measured on the dawn side of the polar cap consistent with the prevailing $B_{y}<0$ conditions. The flow channel speeds intensify this asymmetry.

We shall focus on the ion drift and precipitation profiles on the dawn side. FC 2 starts at a sharp equatorward boundary (flow shear reversal) and more gradually decreasing flow speeds are observed towards higher latitudes. This latitude profile is typical for FC 2. Particle precipitation in the latitude regime of the FC 2 is identified as polar rain (with "strahl" electrons). The relatively intense (compared to neighboring Northern Hemisphere passes) polar rain electron flux (top panel) is consistent with direct entry of the "solar wind strahl" into the Southern Hemisphere polar cap favoured by IMF $B_{x}$ polarity (positive), as documented by Fairfield and Scudder (1985).

Flow channel FC 2 is bordered on its equatorward side by BPS-type precipitation and electron energies extending beyond $1 \mathrm{keV}$. Equatorward of the BPS precipitation a zone of magnetospheric energetic electrons (CPS type), using the terminology of Fairfield et al. (2008) (see their Fig. 2), is detected.

Birkeland current regimes (gradients in the $B_{z}$ deflection in the bottom panel) are identified (from lower to higher latitudes): $\mathrm{R} 2, \mathrm{R} 1 / \mathrm{C} 2$, and $\mathrm{C} 1$. $\mathrm{C} 1$ extends from the FC 2 equatorward boundary towards high latitudes, i.e., covering a wide latitude range. The $\mathrm{C} 2 / \mathrm{R} 1$ regime(s) are latitudinally narrow, coinciding with the BPS type electron precipitation. We note that the identification of the $\mathrm{C} 2$ current is uncertain in this case (see Discussion). R2 is the Birkeland current associated with CPS electron precipitation.

Figure 11 shows F13 data during the interval 12:3213:02 UT. This is the same event category as that of the previous example: $\mathrm{SH}$-dawn $/ B_{y}<0$ (dark). The expected polar cap precipitation for this category is again polar rain containing a "strahl" component. The reversal from sunward to antisunward flow is abrupt (flow shear). FC 2 is delimited by the vertical guidelines. The latitude profiles in the vicinity of flow channel FC 2 are very similar to those reported in the previous case, $3 \mathrm{~h}$ later. This illustrates the stability of the magnetosphere-ionosphere conditions during the passage of 


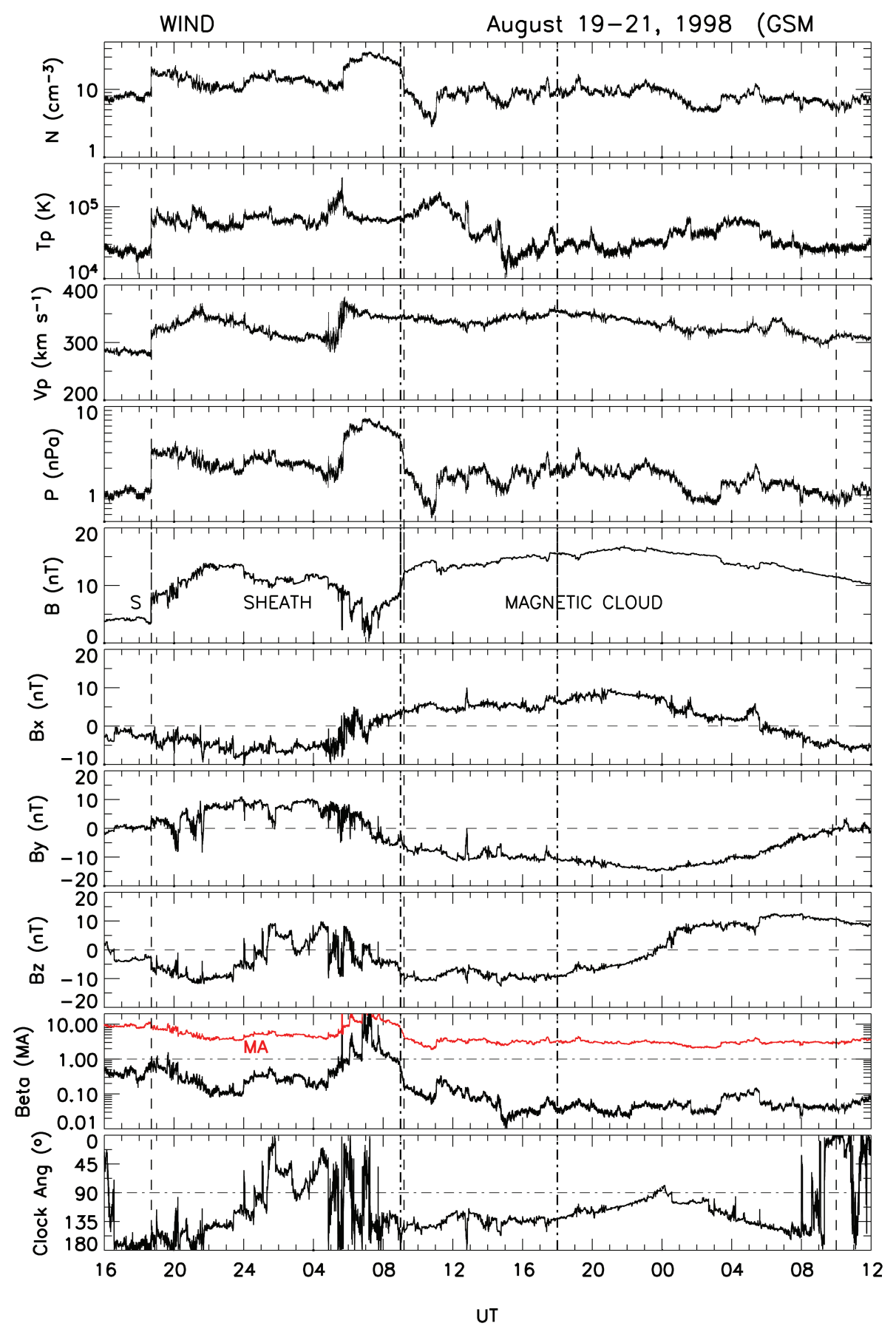

Fig. 8. Solar wind plasma and IMF observations from spacecraft Wind during the interval 16:00 UT (19 August)-12:00 UT (21 August), 1998. Panels from top to bottom shows (i) proton density, (ii) proton temperature, (iii) bulk speed, (iv) solar wind dynamic pressure, (v) IMF total field, (vi-viii) the field components $B_{x}, B_{y}, B_{z}$, (ix) Alfvén-Mach number (red) and proton beta, and (x) the IMF clock angle $(\theta)$. The shock, sheath, and the cloud proper are marked by vertical guidelines.

the interval of stable conditions in the IP cloud (Fig. 8) and consequently the persistence of flow channel FC2.

Figure 12 shows two selected DMSP F13 tracks across the polar cap in the Northern Hemisphere on this day. In this $\mathrm{NH} / B_{y}<0$ case we shall focus on the polar cap boundary on the dusk side (Fig. 1). This is a case with sunlit polar cap ionosphere. The intervals of interest here are: (i) 15:13-15:25 UT, and (ii) 16:52-17:07 UT. We note the following features: along the first track: (i): convection reversal (CR) and polar rain (PR) precipitation on its high-latitude 
side (along the track), (ii) flow channel FC 2 is totally absent (see below); second track: (iii) arc in the vicinity of the convection reversal (CR), (iv) polar rain precipitation and steady antisunward convection convection on the poleward side of the CR.

Figure 13 shows data from a Northern Hemisphere duskdawn pass during the interval 15:04-15:34 UT. The event category is NH-dusk $/ B_{y}<0$. There is a gradual, smooth transition from sunward to antisunward flow at dusk. In this sunlit case no flow channel FC 2 is observed. The BPS precipitation is very weak, which implies a weak conductivity gradient at the polar cap boundary. Polar rain precipitation is detected in the polar cap.

Figure 14 shows F13 data during a dusk-dawn crossing in the Northern Hemisphere during 16:46-17:16 UT. This is event category NH-dusk $/ B_{y}<0$ (sunlit). Thus, this is the same category as shown in Fig. 7 except for the sunlight ionization difference. This is a sunlit case. Five latitudinally separate regimes of Birkeland current/precipitation/convection, corresponding to those indicated in Fig. 7 for the NH-dawn $/ B_{y}>0$ case, have been marked.

(1) C1 current and polar rain with antisunward convection, (2) $\mathrm{C} 1$ current and polar rain with moderate $(1 \mathrm{~km} / \mathrm{s})$ flow channel FC 2, (3) C2 current and arc(s) with slow antisunward convection, (4) R1 current with sunward convection, and (5) R2 current and CPS precipitation (sunward convection).

The C1-C2 Birkeland current regimes shown schematically in Fig. 1a) (top left) are easily identified in this case (see $B_{z}$ gradients in the bottom panel; regimes 2 and 3 ). The energetic $\operatorname{arc}(\mathrm{s})$ at the polar cap boundary is of the type "evening anticorrelation arc"(EAA or inverted - V arc) (see discussion below). Moderate ion drifts of opposite direction are observed on the sides of the arc. The ion drift inside the arc is small (depressed $\mathbf{E}$-field in regime 3).

\subsection{Case 3: 12 December 1999; $B_{y}>0$ : NH-dawn}

We next discuss DMSP F13 passes on 12 December 1999. The components of the IMF are generally steady with $B_{y}>0$, $B_{z}<0$, and IMF clock angle in the regime range $90-135^{\circ}$.

Figure 15 shows WIND data in the same format as for the previous interplanetary plots. The data refer to a fast (leading edge speed $\sim 750 \mathrm{~km} / \mathrm{s}$ ) interplanetary coronal mass ejection (ICME) driving a shock. The shock (S), sheath and the leading edge of the ICME are marked.

Wind was situated at $(-14,-57,16) R_{E}$ and $(-10,-55$, 17) $R_{E}$ at the start and end of the time interval shown, respectively, i.e. it was in the solar wind. The Wind-ground delay is practically zero: The storm sudden commencement (SSC) elicited by the leading shock occurs at 15:51 UT and the shock passes Wind at about this time. The passage at Earth of the ICME lasts until 17:00 UT on 13 December.

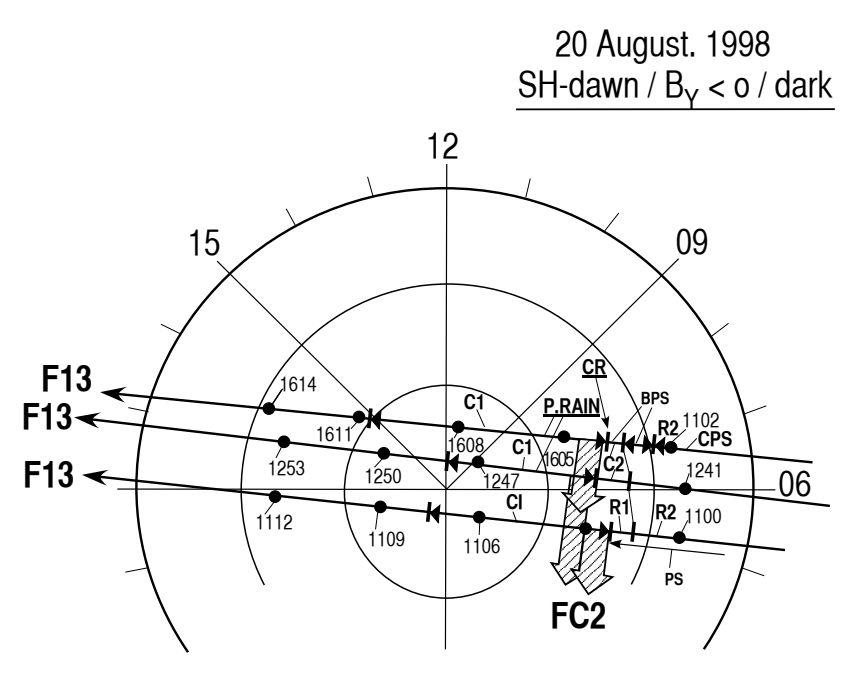

Fig. 9. Three DMSP F13 tracks across the polar cap in the Southern Hemisphere (SH) shown in MLT/MLAT coordinates. The event category is $\mathrm{SH}$-dawn $/ B_{y}<0$ (dark). The following intervals are marked (i) 11:00-11:12, (ii) 12:41-12:53, and (iii) 16:02-16:14 UT. Convection channels are marked by hatched arrows. Particle precipitation (CPS, BPS, P.RAIN) and Birkeland current regimes (R2, R1, $\mathrm{C} 2, \mathrm{C} 1)$ are marked along the different tracks.

We notice the presence of a positive $B_{y}$ component and the $B_{z}$ is $\leq 0$ practically throughout the interval.

Figure 16 shows three DMSP F13 tracks across the polar cap of the Northern Hemisphere. In this $\mathrm{NH} / B_{y}>0$ case we shall focus on the polar cap boundary on the dawn side (Fig. 1b). This is a case with a dark polar cap ionosphere. The intervals we consider are: (i) 12:33-12:48 UT, (ii) 15:57-16:09 UT, and (iii) 22:39-22:54 UT. Flow channel FC 2 is marked for all three cases. It is located within the 70-80 MLAT/06:00-09:00 MLT sector. The equatorward boundary of the polar rain/mantle precipitation regime(s) coincides with the FC 2 equatorward boundary and the convection reversal (CR). Plasma sheet precipitations (BPS and CPS) at lower latitudes are also marked.

Figure 17 shows Northern Hemisphere F13 data for the dusk-dawn pass during the interval 15:48-16:18 UT which has been marked in Fig. 16. This is event category NHdawn $/ B_{y}>0$ (dark). The six vertical guidelines are introduced to mark five latitude regimes with different Birkeland current, particle precipitation, and ion drift characteristics. (1) $\mathrm{C} 1$ current and polar rain with antisunward convection, (2) $\mathrm{C} 1$ current and polar rain with flow channel FC 2 (1$2 \mathrm{~km} / \mathrm{s}$ ), (3) C2 current and LLBL with moderate antisunward convection $(<1 \mathrm{~km} / \mathrm{s})$, (4) R1 current and BPS with fast sunward convection, and (5) R2 current and CPS with depressed sunward convection. 


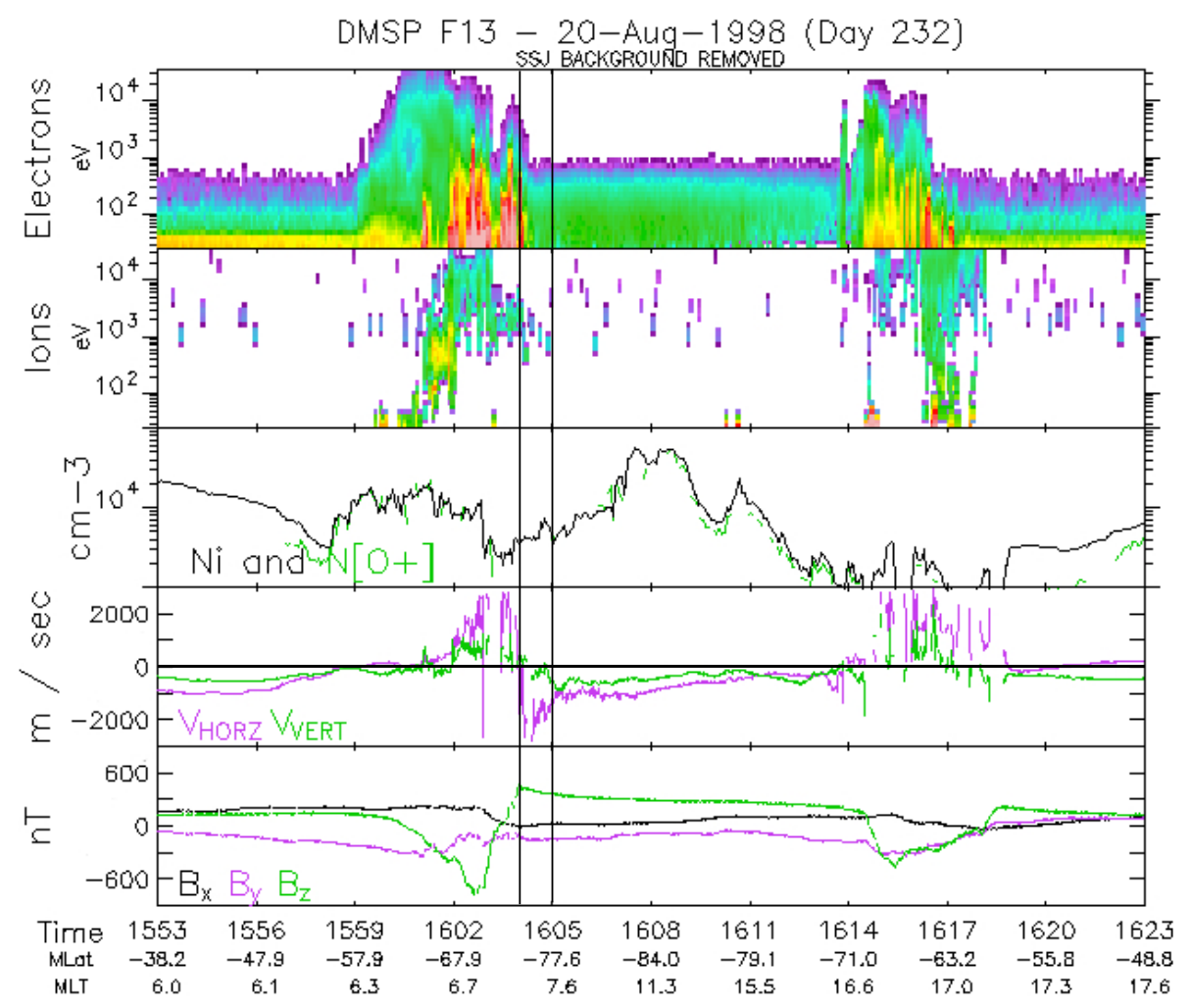

Fig. 10. Southern Hemisphere DMSP F13 data for the interval 15:53-16:23 UT. Cross track ion drift (panel 4) is shown in the context of particle precipitation (panels 1 and 2) and Birkeland current regimes ( $B_{z}$ trace in bottom panel). Flow channel FC 2 in panel 4 is marked by vertical guidelines. Event category: SH-dawn $/ B_{y}<0$ (dark).

\subsection{Case 4: 21 January 2001; $B_{y}<0$ : NH-dusk and SH- dawn}

Data from two further (see Fig. 3) crossings of the polar cap by DMSP F13 on on 21 January 2001, one in each hemisphere, will now be discussed. As an introduction to this case we present the solar wind plasma and IMF data for the interval 15:00-21:00 UT. In this case Wind was very distant from the Sun-Earth line, so we consider ACE magnetic field data. ACE had gaps in the plasma data coverage for the period, so we took SOHO data from the CELIAS instrument. The data resolutions are $1 \mathrm{~min}$ (plasma) and $16 \mathrm{~s}$ (field). The positions of spacecraft at 15:00 UT are $(242.5,-1.7,22.4) R_{E}$ (ACE) and $(194.2,-23.0,16.4) R_{E}$ (SOHO). At 21:00 UT ACE and SOHO were located at $(242.5,-2.2,22.5) R_{E}$ and $(194.2,-22.0,16.5) R_{E}$, respectively.

Figure 18 shows a combination of ACE (magnetic field) and SOHO (plasma) data. ACE data have been time-shifted by $16 \mathrm{~min}$ to account for the convection delay ACE-SOHO. With a low solar wind of $\sim 350 \mathrm{~km} / \mathrm{s}$, we estimate the propagation delay from $\mathrm{SOHO}$ to Earth to be $\sim 65 \mathrm{~min}$. Thus the northward turning at 20:15 UT would arrive at the subsolar magnetopause at $\sim 21: 20$ UT which is about $45 \mathrm{~min}$ later than the precipitation, convection and FAC regimes we discuss below. The IMF conditions relevant to the DMSP F13 pass we discuss (20:20-20:40 UT) are: $B_{x}=2 \mathrm{nT}, B_{y}=-8 \mathrm{nT}$, $B_{z}=-11 \mathrm{nT}$ (clock angle is $\sim 145^{\circ}$ ).

Figure 19 shows the track of spacecraft DMSP F13 across the polar cap in the Northern Hemisphere during the interval 20:28-20:43 UT. In this $\mathrm{NH} / B_{y}<0$ case we shall focus on the polar cap boundary on the dusk side. This is a case with dark polar cap ionosphere. We have marked the presence of the flow channel FC 2 in the context of precipitation zones (CPS, arc, polar rain) and Birkeland current (C1).

Figure 20 shows DMSP F13 data from a dusk-dawn pass in the Northern Hemisphere during the time interval 20:2220:52 UT. The event category is NH-dusk $/ B_{y}<0$ (dark). The ion drift profile at dusk shows the classical signatures of the dusk-side arcs, i.e. (i) enhanced and opposed flows on either sides of the arc, and (ii) strongly depressed flow speed inside the arc (making the flow pattern look like a bifurcated vortex sheet). In this paper our concern is the abrupt onset of strong $(2 \mathrm{~km} / \mathrm{s})$ antisunward convection on the poleward boundary of the arc. At this boundary there is a sharp transition from energetic arc electrons on its equatorward to to polar rain precipitation on its poleward side. The smooth return to lower flow speeds with increasing distance from the boundary is a classical signature of the FC 2 flow channel and sets its boundaries precisely. The characteristic Birkeland current features associated with this dusk arc and its surroundings 


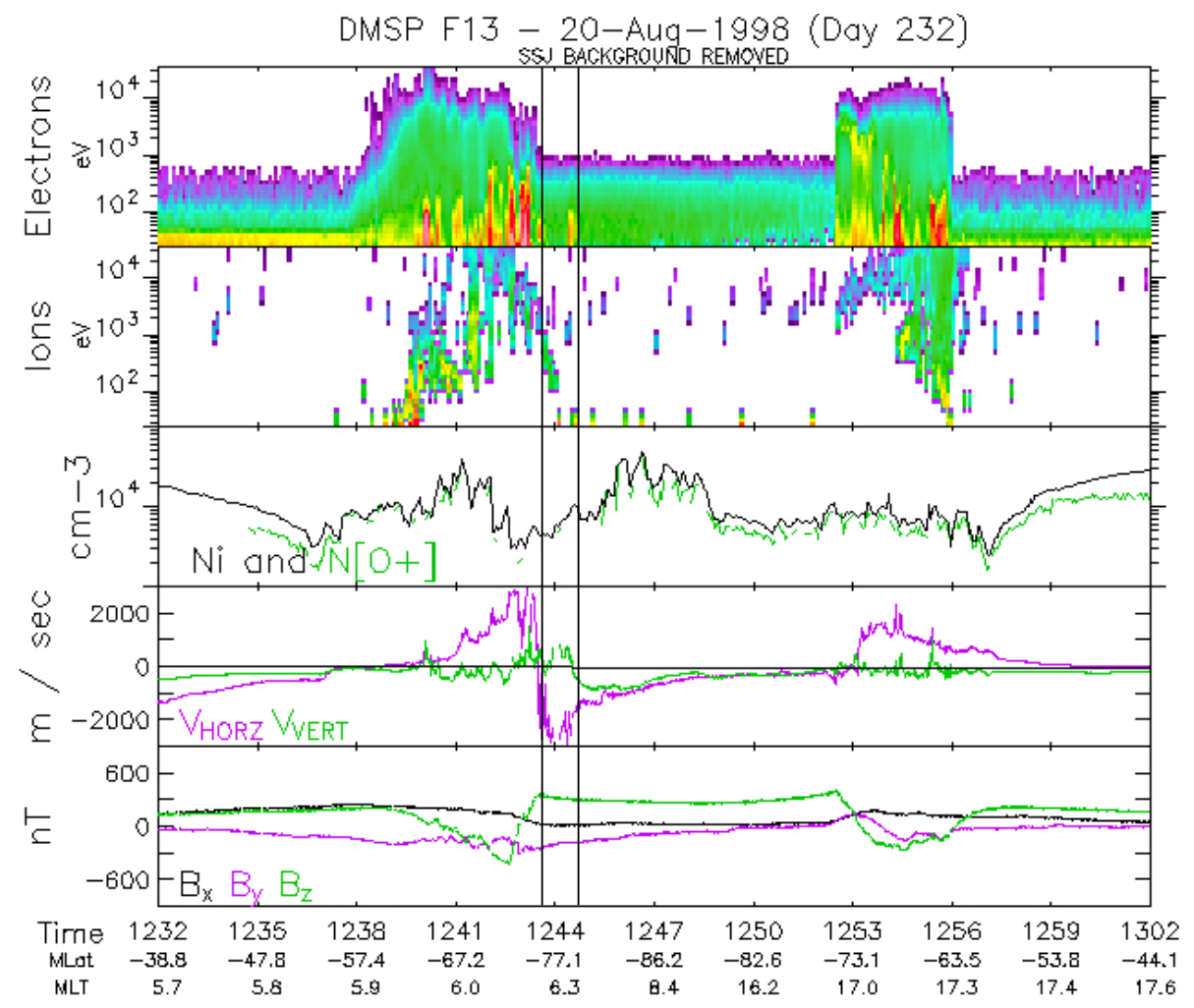

Fig. 11. Southern Hemisphere DMSP F13 data for the interval 12:32-13:02 UT. Flow channel FC 2 (panel 4) is marked by vertical guidelines. Event category is $\mathrm{SH}$-dawn $/ B_{y}<0$ (dark).

reported in Fig. 3 are also seen in this case. We distinguish between five regimes: (1) $\mathrm{C} 1$ current and polar rain precipitation with moderate $(<1 \mathrm{~km} / \mathrm{s})$ antisunward convection, (2) $\mathrm{C} 1$ current and polar rain/LLBL precipitation with flow channel FC 2, (3) C2 current and BPS-type precipitation (evening anticorrelation arcs; EAAs) with depressed ion drift speed, (4) R1 current and enhanced sunward convection, and (5) R2 current and CPS precipitation with moderate sunward convection.

Figure 21 shows an overview of the DMSP F13 track in the Southern Hemisphere during the interval 17:55-18:10 UT. In this $\mathrm{SH} / B_{y}<0$ (sunlit) case we shall focus on the polar cap boundary on the dawn side (Fig. 1). Precipitation regimes CPS, arc and polar rain (P.RAIN) have been marked.

Figure 22 shows DMSP F13 data from the corresponding dawn-dusk pass in the Southern Hemisphere. This is the category for which polar rain with strahl electrons is expected in the polar cap (favoured by the IMF $B_{x}$ polarity). The ion drift goes from strongly sunward to strongly antisunward in the vicinity of the moderate BPS precipitation at the dawn side polar cap boundary. Flow channel FC 2 (antisunward convection at $1.5 \mathrm{~km} / \mathrm{s}$ ) may be identified in this case. There is no sharp poleward boundary of this FC 2. The following four latitude regimes are marked in the figure: (1) polar rain and $B_{y}$-asymmetric polar cap convection at speed $<1 \mathrm{~km} / \mathrm{s}$, (2)

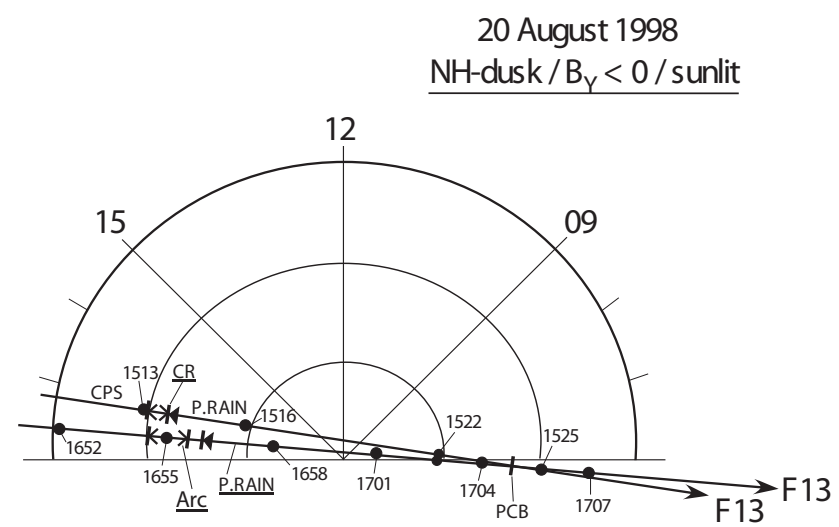

Fig. 12. Two DMSP F13 tracks across the polar cap in the Northern Hemisphere shown in MLT/MLAT coordinates. The event category is NH-dusk/ $B_{y}<0$ (sunlit). The following intervals are marked: (i) 15:13-15:25 UT and (ii) 16:52-17:07 UT. Precipitation regimes are marked along the track.

polar rain and enhanced anisunward convection (approaching $1.5 \mathrm{~km} / \mathrm{s}$ at equatorward boundary), (3) BPS-type electron precipitation and C2/R1-type Birkeland current in the vicinity of the convection reversal, (4) CPS precipitation and R2 Birkeland current. 


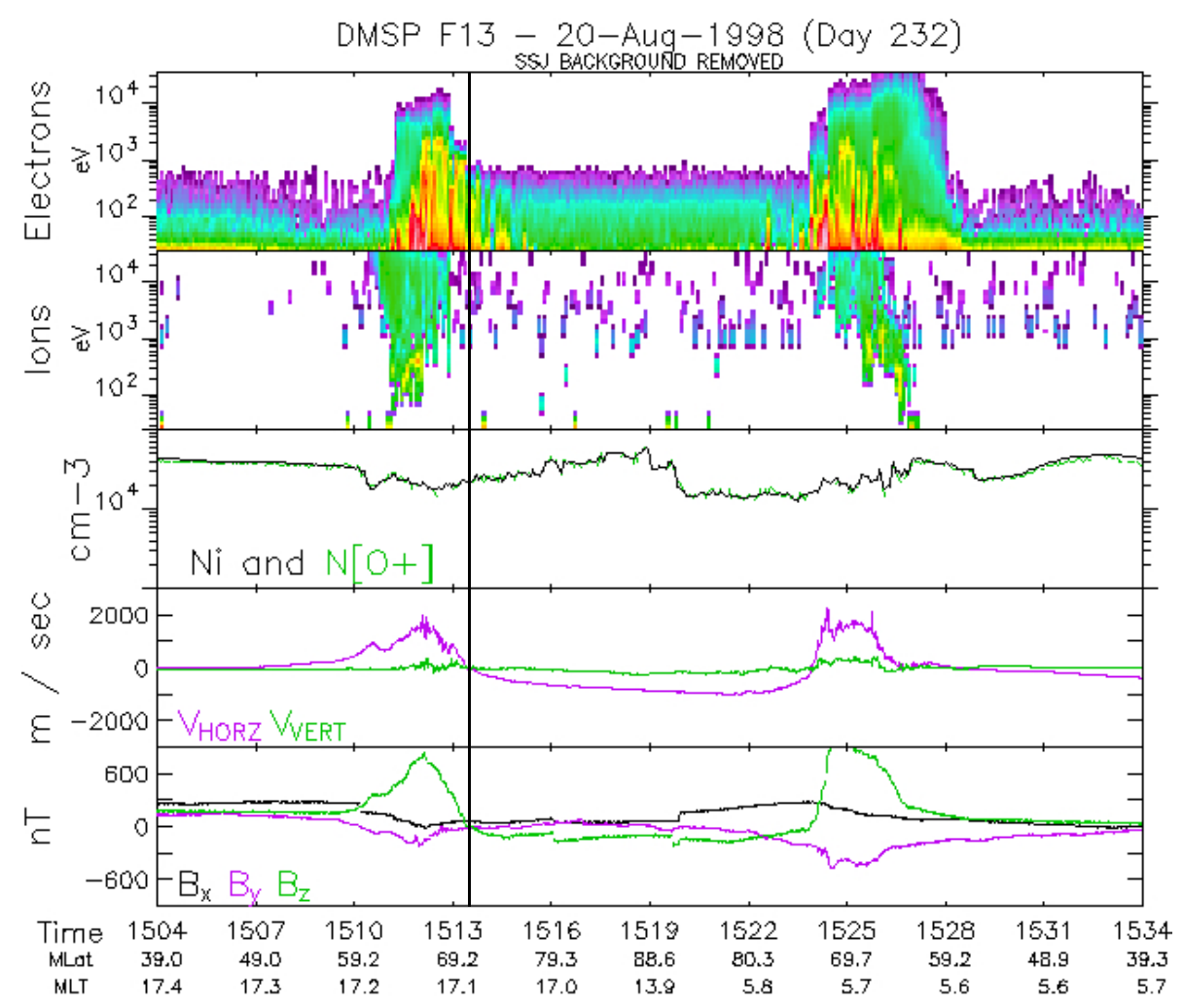

Fig. 13. Northern Hemisphere DMSP F13 data for the interval 15:04-15:34 UT. Polar cap boundary is marked by vertical guideline. Event category: NH-dusk/ $B_{y}<0$ (sunlit).

\subsection{Case 5: 10 January 1997; $B_{y}<0$; SH-dawn (sunlit)}

We finally discuss DMSP F13 data on the last selected day, 10 January 1997. The interplanetary medium consisted of a magnetic cloud.

First we present an overview of the plasma and field data for this much-studied 10 January 1997 IP magnetic cloud (e.g. Farrugia et al., 1998). Wind data are given in Fig. 23. Wind was located at $(84.72,-59.48,-3.39) R_{E}$ and $(93.08$, $-57.55,-4.50)$ at the beginning and end of the day. We notice the stable plasma and field conditions around the time of the DMSP F13 pass we discuss (17:00 UT). The magnetic field components relevant to our study are: $B_{x}=-8 \mathrm{nT}$, $B_{y}=-11 \mathrm{nT}$, and $B_{z}=-1 \mathrm{nT}$ (clock angle $\sim 90^{\circ}$ ).

An overview of the DMSP F13 track in the Southern Hemisphere during the interval 17:06-17:18 UT is shown in Fig. 24. In this $\mathrm{SH} / B_{y}<0$ and sunlit polar cap case we shall focus on the dawn side of the polar cap (Fig. 1a (bottom right)). Thus, this case can be used as an example to check the presence of convection channel FC 2 under sunlit conditions. Is it masked by the conductivity effect due to the fotoionization or not? We shall see that FC 2 is indeed present, with flows peaking at $3 \mathrm{~km} / \mathrm{s}$. The flow channel is placed in the context of particle precipitation regimes CPS, arc (BPS) and polar rain (P.RAIN), and the convection reversal (CR).
Figure 25 shows DMSP data from a polar cap pass in the Southern Hemisphere. Flow channel FC 2 (antisunward drift speed: $1-3 \mathrm{~km} / \mathrm{s}$ ) is marked by vertical guidelines (regime 2 ). FC 2 is bordered on its equatorward side by regime 3 characterized by relatively intense fluxes of BPS-type electron precipitation (top panel) and the associated R1/C2-type Birkeland current directed into the ionosphere in the Southern Hemisphere (bottom panel). FC 2 has a sharp equatorward boundary and a more gradual transition to the ordinary $B_{y}$-asymmetric antisunward convection $(1 \mathrm{~km} / \mathrm{s})$ at its highlatitude boundary in the polar cap. The electron precipitation in the dawn side polar cap including the FC 2 regime is relatively intense polar rain. FC 2 is accompanied by a C1-type Birkeland current directed out of the ionosphere. Thus, the FC 2-Birkeland current association is as indicated in Fig. 1a) (bottom right). Regime 4 in the figure is occupied by the R2 Birkeland current and CPS-type precipitation.

\section{Summary of observations}

In case examples using data acquired by DMSP F13 in crosspolar cap passes, we have documented the presence of channels of enhanced antisunward convection at the polar cap boundary whose position with respect to noon (dawn/dusk) in a given hemisphere depends on the IMF $B_{y}$ polarity 


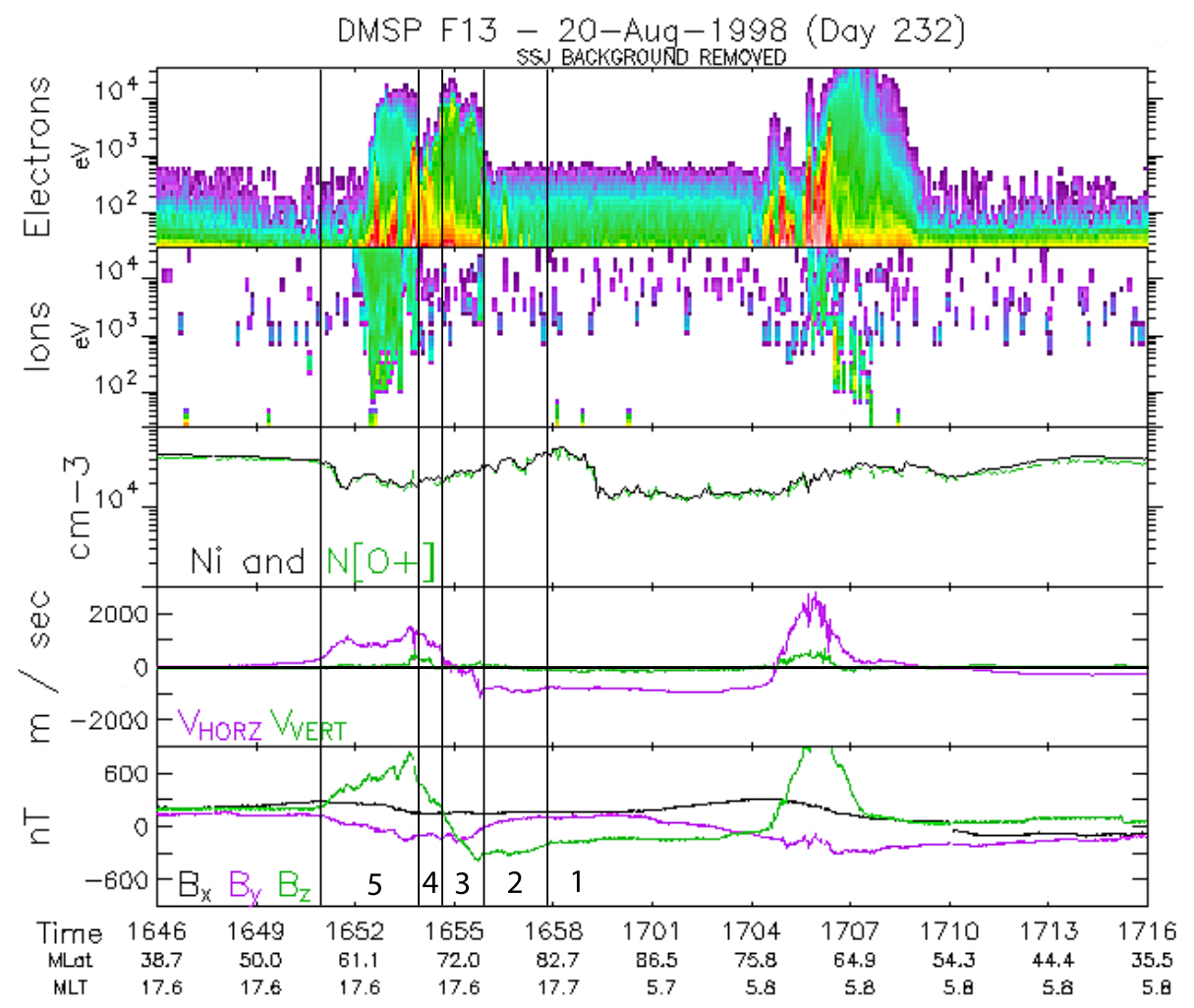

Fig. 14. Northern Hemisphere DMSP F13 data for the interval 16:46-17:16 UT. Precipitation/convection/Birkeland current regimes marked 1-5 are: (1): P.RAIN (central polar cap); (2): P.RAIN and C1 current and moderate FC 2; (3): evening arcs and C2 current; (4): BPS and R1 current; (5): CPS and R2 current. Event category: NH-dusk/ $B_{y}<0$ (sunlit).

(Fig. 1). Three examples were selected from intervals of IP magnetic cloud passages at Earth on 1 October 2002, 20 August 1998, and 10 January 1997. As a part of the dawndusk convection asymmetry the flow channels are located on opposite sides in the Northern and Southern Hemispheres. This flow channel, which we refer to as FC 2, is located immediately poleward of the zone of BPS/LLBL-type auroral precipitation, within the regimes of mantle and polar rain precipitation. From this observation we infer the convection channel to be associated with old open magnetic field lines (reconnection has occurred some time in the past).

In order to investigate the role of ionospheric conductivity and associated polarization effects on this flow channel we reported observations from both the Northern and Southern Hemispheres in cases where the ionosphere is sunlit in one hemisphere and dark in the other. Thus we showed examples of the following types: (i) NH-dawn $/ B_{y}>0$ (sunlit; Figs. 6 and 7), (ii) SH-dawn $/ B_{y}<0$ (dark; Figs. 10 and 11), (iii) $\mathrm{NH}$ dusk $/ B_{y}<0$ (sunlit; Figs. 13 and 14), (iv) NH-dawn $/ B_{y}>0$ (dark; Fig. 17), (v) NH-dusk $B_{y}<0$ (dark; Fig. 20), and (vi) SH-dawn $/ B_{y}<0$ (sunlit; Figs. 22 and 25).

The extra case on 17 April 1999 (SH-dusk/ $B_{y}>0 /$ dark) completes the coverage of the categories shown in Fig. 1. We tested the presence/absence of FC 2 and its relationship to precipitation boundaries and Birkeland currents for all categories. In addition we have reported sunlit and dark ionosphere examples for three of the four categories. Examples (i), (ii), and (vii) demonstrate that flow channel FC 2 can be present even in the case of a sunlit ionosphere. In these cases (10 January 1997 and 21 January 2001) flow channel FC 2 is present in both hemispheres, but this is generally not the case. We note that when FC 2 is strongly present in the sunlit case (e.g., Fig. 22) the polar cap is bordered by a strong flux of BPS precipitation (morning anticorrelation arc). On 21 January 2001 (and 17 April 1999; data not shown) FC 2 is most pronounced in the dark hemisphere (compare Figs. 20 and 22). Below we shall discuss the reasons for the occasional presence of FC 2 in the sunlit ionosphere.

The ion drift profile in the vicinity of flow channel FC 2 on the dusk side is shown schematically in Fig. 26 for $\mathrm{IMF} /$ hemisphere categories $\mathrm{NH} / B_{y}<0$ and $\mathrm{SH} / B_{y}>0$. An example of the former event category is the 21 January 2001 case (see Figs. 19 and 20). The latter event category is also observed in the case of the magnetic cloud passage at Earth on 17 April 1999 (not shown).

Positive ion drifts $\left(V_{y}\right)$ are sunward while negative are antisunward. Enhanced subauroral ion drift is marked SAPS (subauroral polaraization stream; see Foster and Vo, 2002). 


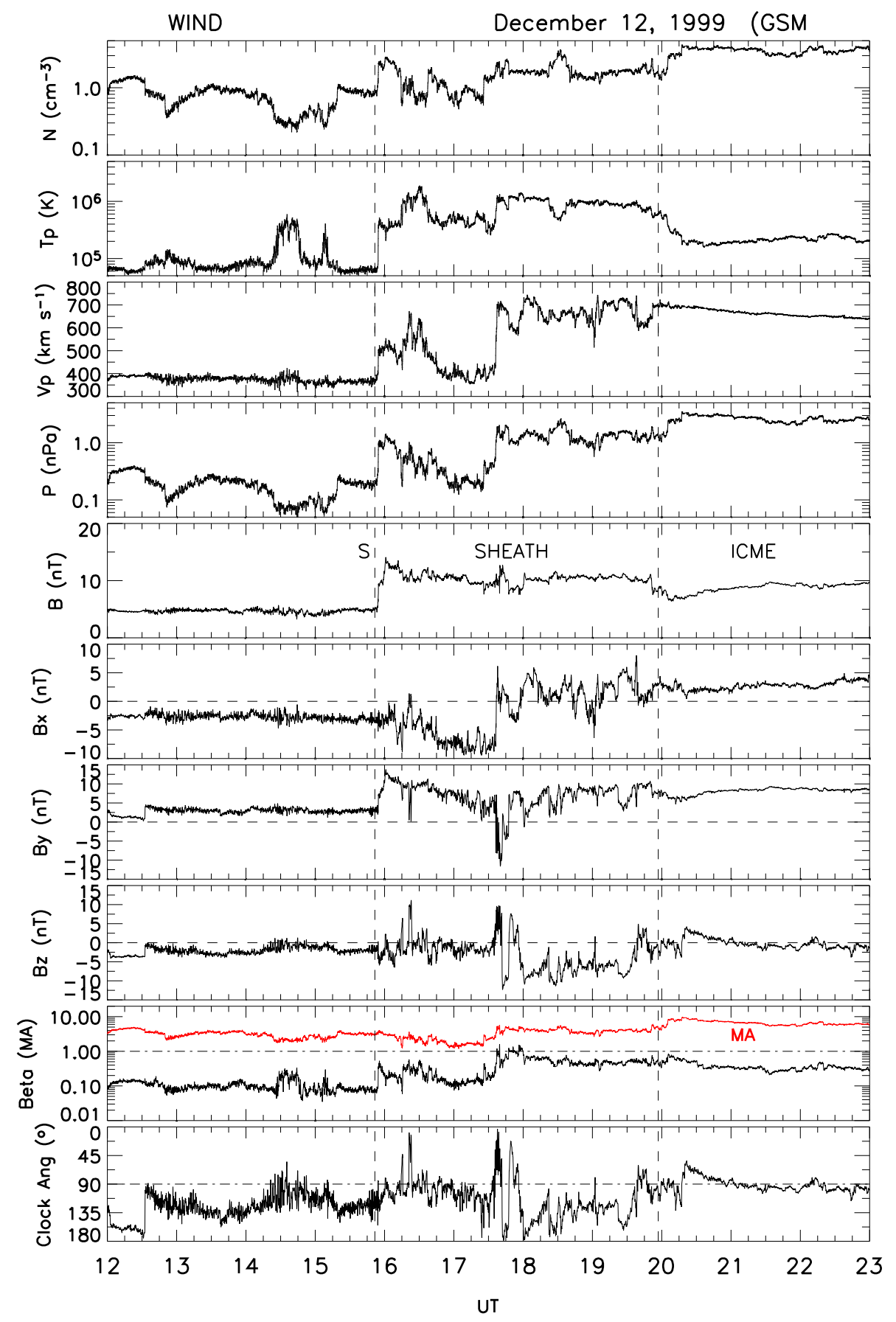

Fig. 15. Solar wind plasma and IMF data obtained from spacecraft Wind during the interval 12:00-23:00 UT. The shock, sheath, and the leading part of an interplanetary CME (ICME) have been marked by vertical guidelines. The format is the same as that of Fig. 4 .

The polar cap is characterized by antisunward flow with a dawn-dusk asymmetry typical for the combinations of hemisphere and IMF $B_{y}$ polarity shown in this case $\left(\mathrm{NH} / B_{y}<0\right.$ and $\mathrm{SH} / B_{y}>0$ ). The strongly enhanced antisunward flow observed when approaching the auroral boundary from the polar cap on the dusk side is our flow channel FC 2. Being located on the side of the polar cap with the fastest antisunward flows, flow channel FC 2 intensifies the IMF $B_{y}$-related dawn-dusk asymmetry in plasma convection. FC 2 is colocated with the most equatorward extension of the polar rain precipitation. The flow pattern on the dusk side polar cap boundary is that of a bifurcated vortex sheet. The evening arc forms a slow-speed region in between the opposing flows on either side (see also Kullen et al., 2008, and references therein). 
Four Birkeland current regimes on the dusk side are marked R2, R1, C2 and C1. Current directions are shown by arrows in Fig. 26. The indicated bifurcation of the outwarddirected current with respect to the convection reversal (R1 versus $\mathrm{C} 2$ ) is observed in many cases. But this distinction between the $\mathrm{R} 1$ and $\mathrm{C} 2$ currents is not always present, i.e., $\mathrm{C} 2$ (poleward of CR) is not always present at the longitude of the local F13 pass.

From the ion drift profile we infer that the electrodynamics of the arc bordering the FC 2 on its equatorward (left) side is of the type referred to as an "evening anticorrelation arc" (EAA), following the terminology of Marklund (1984). In our case the arc is bordered on both sides by convection channels with different flow direction. The ion drift (E-field) is strongly reduced in the center of the arc. The latter property is the source of the term "anticorrelation arc". The latitude profiles of the electric field and the ionospheric conductivity are anticorrelated in the vicinity of the arc. In previous studies focus has been placed on the channel of enhanced sunward flow on the equatorward side of evening arcs, marked FC 0 (Marklund, 1984). (The symbol FC 1 is reserved for the flow channel on "newly open field lines" to be consistent with our previous notation.) In this study we investigate the properties of the flow channel on the poleward side of the evening arcs, our FC 2.

The ion drift profile in the vicinity of flow channel FC 2 on the dawn side is shown schematically in Fig. 27. This is the hemisphere/ $B_{y}$ polarity combination with enhanced polar rain in the form of the solar wind "strahl". This is the fieldaligned component of the electron halo distribution which carries heat flux from the Sun's corona directly into the hemisphere favoured by IMF $B_{x}\left(B_{y}\right)$ polarity (Fairfield and Scudder, 1985; Gussenhoven, 1989).

We note the abrupt convection enhancement on the poleward boundary of the auroral precipitation (BPS/LLBL) and the more gradual decrease towards higher latitudes, i.e. the similar latitude profile as for the dusk side FC 2 shown in Fig. 26. FC 2 is bordered on the poleward side by the standard $B_{y}$-asymmetric polar cap convection. The $\mathrm{C} 2$ and R1 currents are associated with antisunward and sunward ion drifts, respectively.

Figures 26 and 27 show that the dusk-side FC 2 and ordinary polar rain occur for the following combination of hemisphere and $B_{y}$ polarity: $\mathrm{NH} / B_{y}<0$ and $\mathrm{SH} / B_{y}>0$. The dawn-side FC 2 and polar rain with the "strahl" component occur for the combination $\mathrm{NH} / B_{y}>0$ and $\mathrm{SH} / B_{y}<0$.

The ion drift profiles in Figs. 26 and 27 are those typically observed in cases when the ionosphere is dark and occasionally when it is sunlit. In cases of a sunlit ionosphere flow channel FC 2 is often totally absent or only weakly present. The absence of FC 2 occurs in the NH-dusk/ $B_{y}<0$ (sunlit) case at 15:13 UT on 20 August 1998 (Fig. 13). This case is characterized by a very weak BPS precipitation at dusk and a correspondingly weak conductivity gradient at the polar cap boundary is expected. Smooth and strongly correlated traces

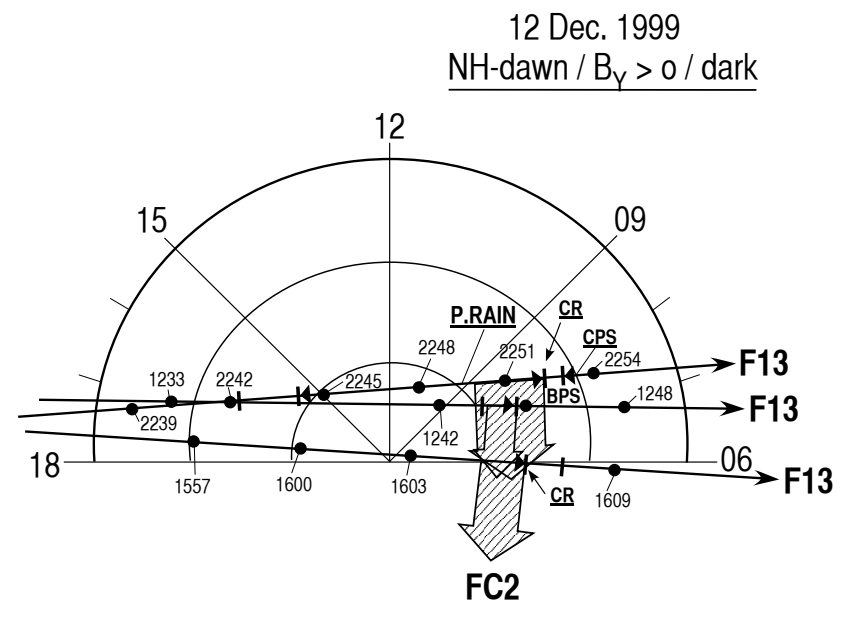

Fig. 16. Three DMSP F13 tracks across the polar cap in the Northern Hemisphere. The event category is: NH-dawn $/ B_{y}>0$ (dark).

of ion drift $\left(V_{\mathrm{HORZ}}\right)$ and magnetic deflection $\left(B_{z}\right)$ are seen. The moderate presence of FC 2 at 16:55 UT on the same day is shown in Fig. 14. In the latter case a very energetic evening arc (inverted $-\mathrm{V}$ arc) is present under the sunlit conditions. These observations indicate that enhanced particle precipitation fluxes and the associated conductivity gradients may compensate for the sunlit conditions and allow FC 2 to form.

The more exceptional case for sunlit conditions is the pronounced FC 2 observed on 10 January 1997 (Figs. 24 and 25). In this case the dawn side polar cap is bordered by a large flux of BPS-type electron precipitation. Clearly this precipitation boundary (morning anticorrelation arc - polar rain) gives rise to a pair of strong flow channels FC 0/FC 2 even in the case of a sunlit ionosphere.

These data exemplify two basic features of solar windmagnetosphere-ionosphere coupling at dawn and dusk: (i) the effect of ionospheric conductivity gradients at auroral boundaries on the ionospheric $\mathbf{E}$-field/ion drift profile (flow channels FC 0 and FC 2), and (ii) FC 2 as the result of momentum transfer from the solar wind along magnetic field lines threading polar rain precipitation, which we refer to as "old open" field lines (reconnection has occurred in the past). Feature (i) may give rise to some deviation from mirror symmetry of the ion drift profiles in Figs. 26 and 27 when one hemisphere is sunlit and other is dark, as demonstrated by the 21 January 2001 case (Figs. 20 and 22). These two aspects of the observations will be discussed in greater detail below.

\section{Discussion}

The basic rationale for this paper is that plasma convection on open field lines can be subdivided in two distinct stages corresponding to "newly open" and "old open" field lines. The topic of this paper is the newly discovered convection 


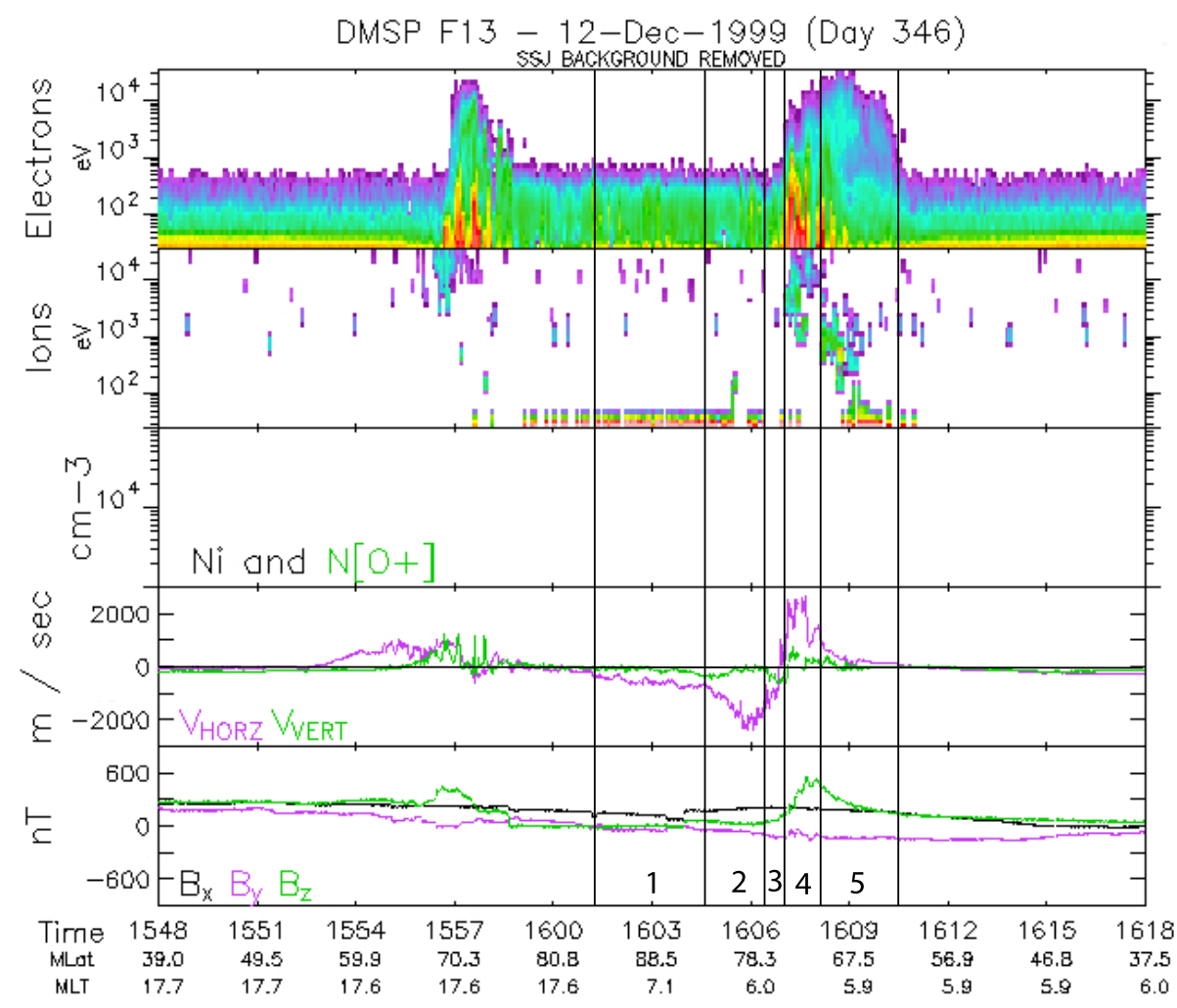

Fig. 17. Northern Hemisphere DMSP F13 data for the interval 15:48-16:18 UT. Precipitation/Birkeland current/convection regimes marked 1-5 are: (1): P.RAIN (central polar cap); (2): P.RAIN, C1 current and flow channel FC 2; (3): P.RAIN/LLBL and C2 current; (4): BPS and R1 current; (5): CPS and R2 current. Event category: NH-dawn $/ B_{y}>0$ (dark).

channels in the second stage and their role in the excitation of an IMF $B_{y}$-related dawn-dusk convection asymmetry. Our most important conclusion is that these flow channels demonstrate the presence of a channel of momentum transfer from the solar wind along "old open" field lines associated with polar rain precipitation. Although the relationship to the first stage in the convection cycle, flow channels on newly open field lines (FC 1), is not the focus of this paper a brief comment is appropriate here. We consider flow channel FC 2 as basically a spatial structure, but the open field line evolution includes a prehistory initiated by pulsed magnetopause reconnection, as witnessed by the phenomenon of poleward moving auroral forms (PMAFs). Associations between PMAFs, flux transfer events (Russell and Elphic, 1978) and Southwood (1987) - type flow channels in the cusp region were first reported and illustrated in a series of Lockwood, Sandholt, and Cowley papers in 1989/1990 (see e.g. Sandholt et al., 1990). Later advances on the spatialtemporal structure of aurora, Birkeland currents and convection in the first stage of the evolution of open field lines in the MLT sectors $\sim 09: 00-12: 00$ and $\sim 12: 00-15: 00$ MLT have established a consistent picture of the poleward propagation of the auroral activity (PMAFs) and corresponding activations of latitudinally separate current sheets (R2-R1-
C2-C1) (Sandholt and Newell, 1992; Farrugia et al., 2003, 2004b).

Recent advances in our knowledge of plasma convection and aurora in the early stage of the open field line evolution (newly or recently reconnected field lines), based on EISCAT Svalbard radar data in combination ground optics, have been reported by Oksavik et al. (2004), Rinne et al. (2007) and Moen et al. (2008). In the latter work the PMAFs/postnoon/ $B_{y}>0$ activity is placed in the context of Birkeland current sheets and flow channel FC 1. Here we have applied the classification of PMAF categories in terms of IMF $B_{y}$ polarity and MLT sector (prenoon/postnoon) as reported by Sandholt and Farrugia (2007a): (i) PMAFs/prenoon $/ B_{y}>0$, (ii) $\mathrm{PMAFs} /$ postnoon $/ B_{y}>0$, (iii) $\mathrm{PMAFs} /$ prenoon $/ B_{y}<0$, and (iv) PMAFs/postnoon $/ B_{y}<0$. The separation of the PMAFs/prenoon and PMAFs/postnoon activities (for both $B_{y}$ polarities) by a strongly attenuated auroral emission (the "midday gap" aurora) is a central feature of the auroral morphology (Farrugia et al., 2004b; Sandholt and Farrugia, 2007a).

The essential element of the connection between PMAFs and the convection channels at dawn-dusk we document in this paper (NH-dawn/ $B_{y}>0, \mathrm{SH}-$ dusk $/ B_{y}>0$, 


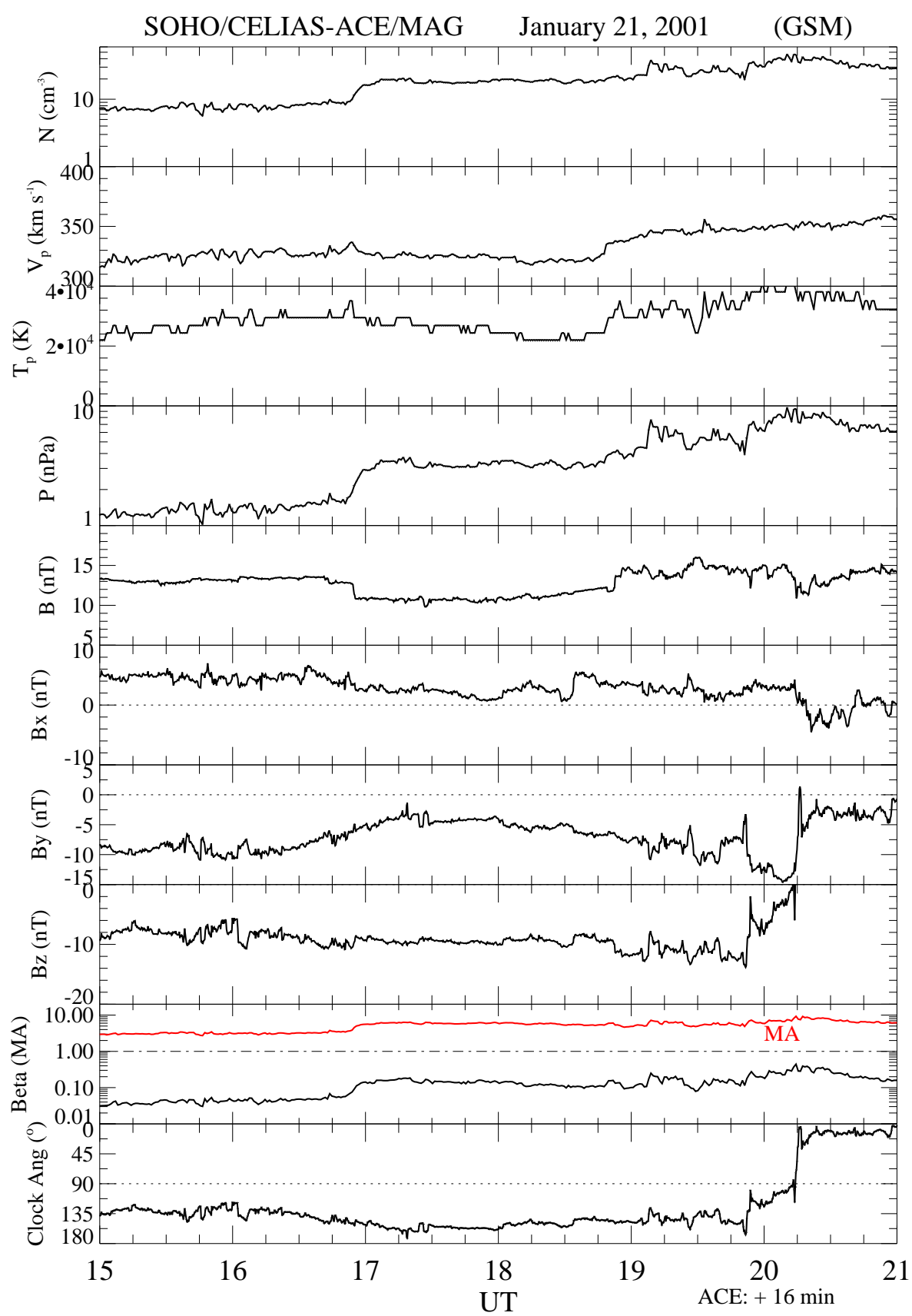

Fig. 18. Solar wind plasma and IMF data for the interval 15:00-21:00 UT obtained from spacecraft SOHO (plasma) and ACE (magnetic field), respectively. Same format as in Fig. 4.

NH-dusk $/ B_{y}<0$, and SH-dawn $\left./ B_{y}<0\right)$ is the Birkeland current pair we call $\mathrm{C} 1-\mathrm{C} 2$ (corresponding to the HCCLCC currents of Taguchi et al., 1993). The highestlatitude stage(s) of PMAFs/prenoon ( 09:00 MLT) and PMAFs/postnoon $(\sim 15: 00$ MLT) have been connected with mantle precipitation and the $\mathrm{C} 1-\mathrm{C} 2$ currents (see Farrugia et al. (2003) and Sandholt and Farrugia (2007a).

The $\mathrm{C} 1-\mathrm{C} 2$ currents in the sectors further away from noon (downstream side of the cusp; 06:00-09:00 and 15:00-
18:00 MLT), which is the topic of this paper (Fig. 1), are associated with polar rain precipitation where auroral emission is practically absent. We conclude that the latter observations represent a later stage of open field line evolution after the PMAFs activity has faded. Momentum transfer from the solar wind at this later stage can be explained by the interconnection geometry shown schematically in our Fig. 1.

In previous studies the IMF $B_{y}$-related dawn-dusk asymmetry in polar cap convection and the associated 


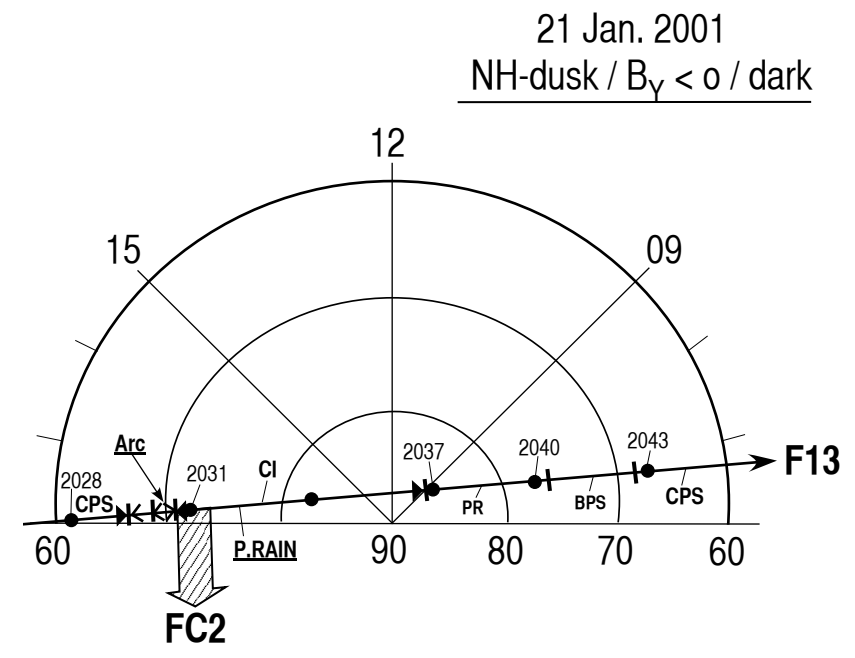

Fig. 19. DMSP F13 track across the polar cap in the Northern Hemisphere. The event category is: NH-dusk $/ B_{y}<0$ (dark). Polar rain precipitation, flow channel FC 2, and the arc on its equatorward boundary have been marked. $\mathrm{C} 1$ represents Birkeland current in the P.RAIN regime.

Svalgaard-Mansurov (S-M) effect have been widely attributed to magnetic tension forces acting on "newly open field lines" (see Introduction). In recent studies we demonstrated the presence of an important extra contribution to the dawn-dusk convection asymmetry and the S-M effect via solar wind - magnetosphere - ionosphere coupling acting on "old open field lines" (Sandholt et al., 2004; Farrugia et al., 2004a; Sandholt et al., 2006b; Sandholt and Farrugia, 2007a,b). This is the few hundred $\mathrm{km}$ wide channel of enhanced antisunward convection (our FC 2) which under certain conditions (nonzero IMF $B_{y}$, ionospheric conductivity gradient) is observed at the dawn/dusk boundaries of the polar cap. The relationships between FC 2 and Birkeland currents $(\mathrm{C} 1 / \mathrm{C} 2)$ and the polar cap boundary arcs for the IMF $B_{y}<0$, Northern Hemisphere/dusk case are illustrated in Fig. 3.

In this study we aim at a more systematic classification of the different variants of this flow channel in terms of (i) IMF $B_{y}$ polarity, (ii) hemisphere (N/S), (iii) the dawn/dusk sides of the polar cap, and (iv) the conductivity gradient at the polar cap boundary.

Flow channel FC 2 occurs at the boundary between polar rain precipitation ("old open field lines") and arcs of plasma sheet or LLBL origin. This is the side of the polar cap where the antisunward ion drift and polar rain precipitation maximize during intervals of nonzero IMF $B_{y}$ (Mozer et al., 1974; Meng et al., 1977). As indicated above we sorted the different categories of these polar cap boundary events by hemisphere (N/S), $B_{y}$ polarity and dawn/dusk MLTs. Thus, the cases we investigate are: (i) $\mathrm{NH}$-dusk $/ B_{y}<0$, (ii) $\mathrm{SH}$ dusk $/ B_{y}>0$, (iii) $\mathrm{NH}$-dawn $/ B_{y}>0$, and (iv) $\mathrm{SH}$-dawn $/ B_{y}<0$
(Fig. 1). The additional effect we consider is the different ionospheric conductivity conditions in the sunlit versus the dark ionospheres.

In the summary Figs. 26 and 27 we demonstrated the presence of the same latitude profiles of flow channel FC 2 in these cases: (i) $\mathrm{NH}$-dusk/ $B_{y}<0$ (dark) and $\mathrm{SH}$-dusk/ $B_{y}>0$ (dark) and in cases (ii) NH-dawn $/ B_{y}>0$ (dark) and SHdawn $/ B_{y}<0$ (dark). This means that the FC 2 profiles in NHdusk/ $B_{y}<0$ and $\mathrm{SH}$-dawn/ $B_{y}<0$ as well as NH-dawn/ $B_{y}>0$ and $\mathrm{SH}$-dusk/ $B_{y}>0$ are mirror images of each other.

We also observed differences in the dawn- and dusk side profiles (deviations from mirror symmetry), appearing on the equatorward side of FC 2 (the C2/BPS current/precipitation regime). The ion flow speed inside the dusk side arc (the evening anticorrelation arc (EAA) and C2/R1 Birkeland current) is strongly depressed (Fig. 26). A corresponding field depression is generally not seen in the dawn side cases (Fig. 27). This dawn-dusk asymmetry is related to the polarity of the C2/R1 Birkeland currents (in or out of the ionosphere) which is opposite in the dawn (in) and dusk (out) cases. This is the cause of the observed deviation from mirror images in the two ion drift profiles.

By using the case examples presented above we shall study the electrodynamics of the different types of arcs for the conditions of dark and sunlit ionospheres. Based on these observations we shall be able to infer the conditions for the occurrence of flow channel FC 2 and to discuss the M-I coupling associated with this enhanced antisunward flow.

The essential elements of the arc electrodynamics are the latitude profiles of ion drift (E-field) and Birkeland current in the vicinity of the arc at the polar cap boundary. Generally these arcs are related to the flow shear at the polar cap boundary and for that reason they are often called "flow shear arcs" (FSAs) (Reiff et al., 1978). So, we shall focus on the ion drift ( $V_{\mathrm{HORZ}}$ ) and $B_{z}$ curves in the DMSP F13 data. In our data set we shall distinguish between two basically different latitude profiles: (i) the case when $V_{\mathrm{HORZ}}$ and $B_{z}$ are strongly correlated (same smooth latitude profiles in both parameters), and (ii) the case with strong (abrupt) deflections in the $V_{\text {HORZ }}$ profile which is not accompanied by a corresponding deflection in $B_{z}$ (see e.g. Smiddy et al., 1980). According to the arc classification of Marklund (1984) category (i) is called a "Birkeland current arc", while category (ii) is a "polarization arc". In reality there is a continuous transition of arc characteristics ranging from one extreme case to the other depending on the relative importance of the roles played by the polarization E-field and the Birkeland current for the observed arc electric field.

Applied to the dusk side boundary the "polarization arc" is called an "evening anticorrelation arc" (EAA) while the "Birkeland current arc" at dusk often appears as an "inverted - V" arc. The EAA is characterized by a polarization E-field in the arc which opposes the ambient field so that the total field is strongly reduced inside the arc. The enhancement of the field outside the arc is due to the ionospheric Pedersen 


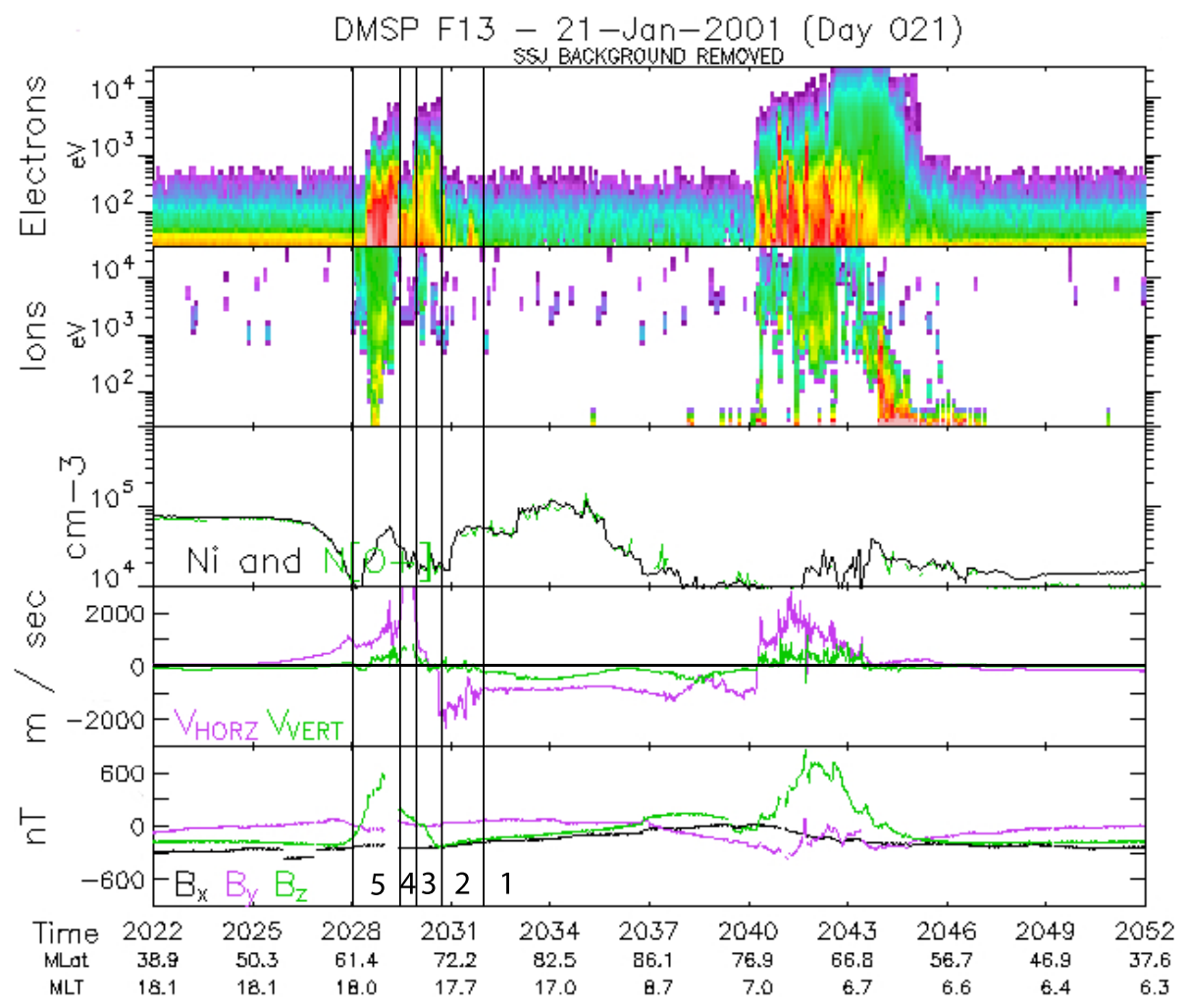

Fig. 20. Northern Hemisphere DMSP F13 data for the interval 20:22-20:52 UT. Precipitation/convection/Birkeland current regimes marked in the figure are: (1): P.RAIN (central polar cap); (2): P.RAIN and C1 current and flow channel FC 2; (3): BPS (evening arcs) and C2 current; (4) BPS and R1 current; (5): CPS and R2. Event category: NH-dusk/ $B_{y}<0$ (dark).

current closure of Birkeland currents. The low conductivity outside the arc is compensated for by a strong $\mathbf{E}$-field. Thus the R1/R2 currents on the dusk side give rise to enhanced sunward flow on the equatorward side of the arc at dusk (FC $0)$. Our flow channel FC 2 is located on the poleward side of the arc, associated with lower conductivity in the polar cap ionosphere (only polar rain precipitation) and the Pedersen current closure of the paired Birkeland currents marked C1 and $\mathrm{C} 2$ in Figs. 26 and 27. This current circuit applies to both the dawn - and dusk side cases.

In our data set we have examples of both categories of arcs. A good example of the EAA is given in the NH-dusk/ $B_{y}<0$ (dark) case shown in Fig. 20 (see also schematic illustration in Fig. 26). Well defined flow channels are seen on both sides of the arc. FC 2 is strongly present on the dusk side polar cap boundary (polar rain precipitation) in this case.

We now compare this case with a sunlit case with the same $B_{y}$ polarity and hemisphere (NH-dusk/ $B_{y}<0 /$ sunlit) shown in Figs. 13 and 14. In the case of the dusk side pass shown in Figs. 13 (15:13 UT) FC 2 is totally absent. We also notice the smooth and well correlated $V_{\mathrm{HORZ}}$ and $B_{z}$ curves. In this case no polarization field is present at the polar cap boundary. The second pass (16:55 UT; Fig. 14) shows, however, a somewhat different arc electrodynamics. Clear boundary

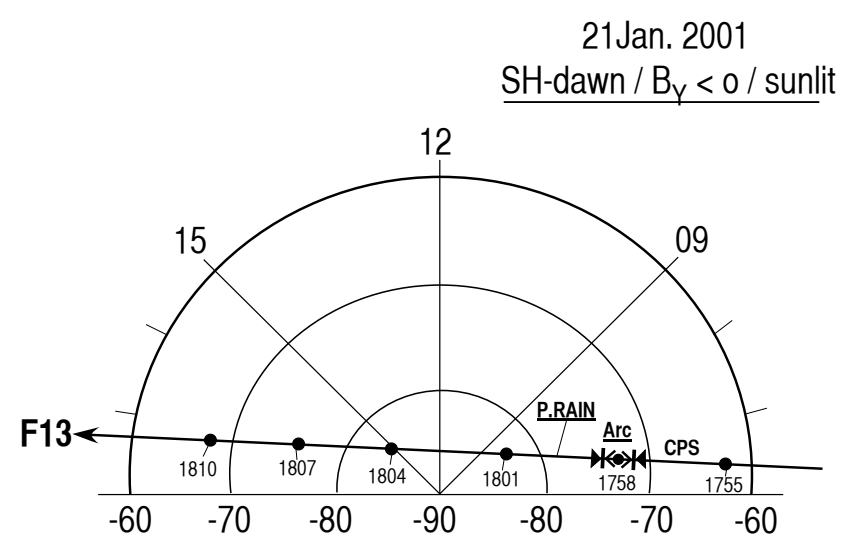

Fig. 21. DMSP F13 track across the polar cap in the Southern Hemisphere. Precipitation/Birkeland current/convection regimes marked in the figure are: (1): P.RAIN; (2) P.RAIN and FC 2 and C1 current; (3): morning arcs and C2/R1 currents; (4): CPS and R2 current. The event category is: $\mathrm{SH}-\mathrm{dawn} / B_{y}<0$ (sunlit).

arcs are present with (i) reduced ion drift inside and (ii) flow channel FC 0 on its equatorward side. An abrupt increase of the antisunward ion drift is seen on the polar cap side of the arcs. This we may call an FC 2, even though its poleward 


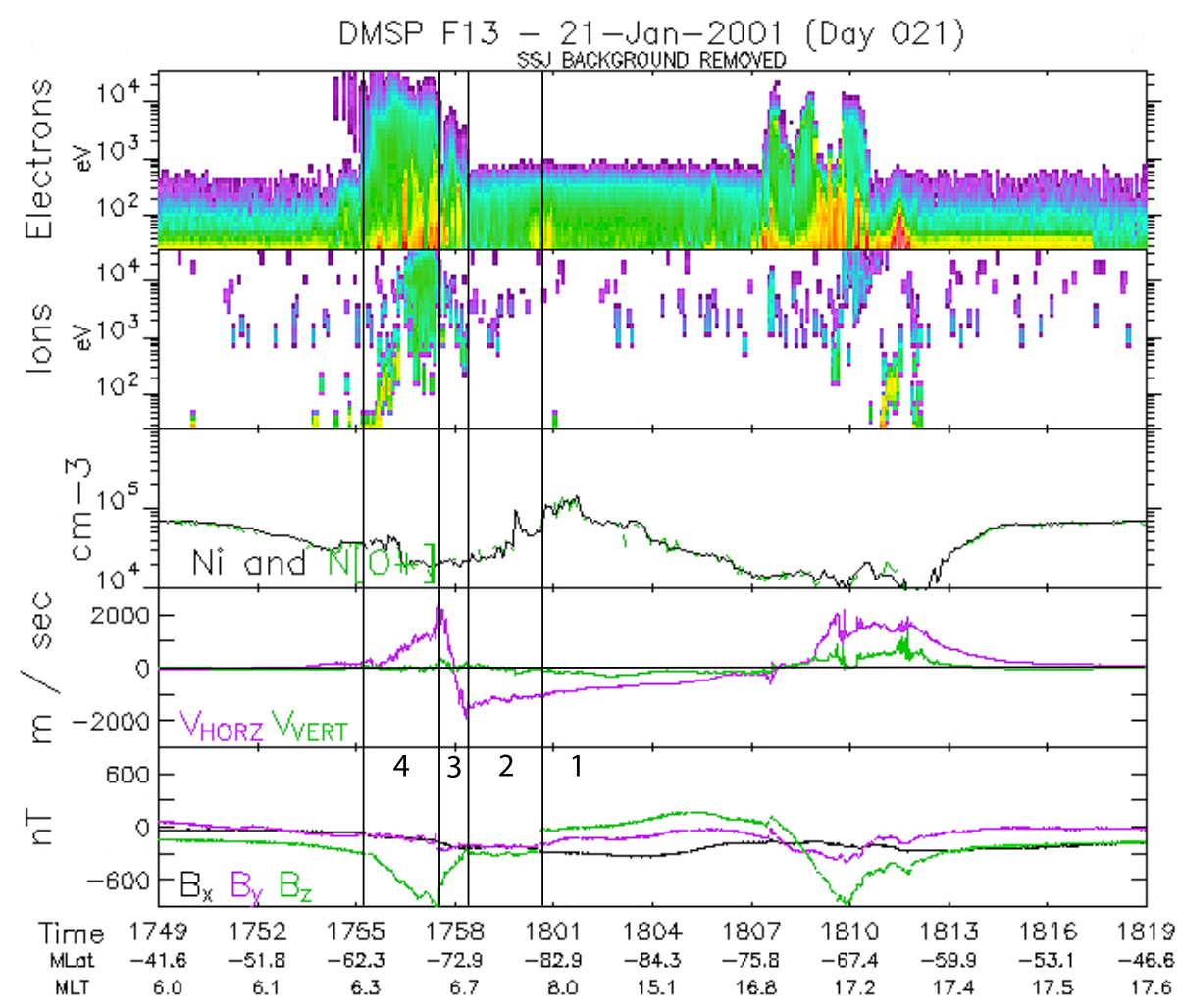

Fig. 22. Southern Hemisphere DMSP F13 data for the interval 17:49-18:19 UT. Precipitation/Birkeland current/convection regimes marked are: (1): P.RAIN (central polar cap); (2): P.RAIN and C1 current and FC 2; (3): morning BPS and C2/R1 currents; (4): CPS and R2 current. Event category: SH-dawn $/ B_{y}<0$ (sunlit).

boundary is not so well defined as in the dark ionosphere cases. We note that well-defined Birkeland current regimes $\mathrm{C} 1, \mathrm{C} 2, \mathrm{R} 1$, and R2 (see Fig. 26) may be inferred from the $B_{z}$-trace in the bottom panel in Fig. 14. C2 (directed out) is associated with the energetic electron arc located at the polar cap boundary. FC 2 is confined to the most equatorward extension of the polar rain precipitation. $\mathrm{C} 1$ is a relatively weak current (small $B_{z}$ gradient) covering a large latitudinal range in the polar cap.

Based on these data we infer that the association between Birkeland currents and the ionospheric Pedersen current $\left(\boldsymbol{J}_{\boldsymbol{P}}\right)$ closure is as indicated by arrows in Figs. 26 and 27. The paired Birkeland currents $\mathrm{C} 1$ and $\mathrm{C} 2$ are closed in the ionosphere via the ionospheric Pedersen current along the electric field. The $\mathrm{C} 2$ current is the current flowing adjacent to the R1 current (on the poleward side), in the latitude regime of the "flow shear arc" (FSA) at the polar cap boundary (see also Fig. 3). In our view C2 corresponds to the "extra downstreamside cleft-associated R1 current" of Watanabe et al. (1996) (see their Fig. 7). In some of the reported examples FC 2 is present although the distinction R1/C2 is not easily identified, or totally absent (only R1 is present at the longitude of the F13 pass). This may be explained by the longitudinal limitation of the C2 current (Watanabe et al., 1996) (see their Fig. 7).
It is apparent that both the degree of flow shear and the conductivity gradient in the ionosphere are important elements in the electrodynamics of the polar cap boundary arcs at dawn/dusk MLTs. In the case of sunlit ionosphere and weak BPS/LLBL-type precipitation the conductivity gradient is small and FC 2 can be totally absent (see example Figs. 13). The other extreme is the dark cases with a sharp poleward boundary of intense fluxes of BPS/LLBL type precipitation (Figs. 10, 11 and 20). In those cases flow channel FC 2 consists of fast $(2-3 \mathrm{~km} / \mathrm{s})$ antisunward flows. Figure 25 (10 January 1997 IP cloud case) is a sunlit case with fast $(3 \mathrm{~km} / \mathrm{s})$ antisunward flow. In this case the conductivity gradient is provided by the intense fluxes of BPS-type precipitation at the polar cap boundary. This is the $\mathrm{SH}$-dawn $/ B_{y}<0$ (sunlit) case showing the ion drift/precipitation profile which is similar to the $\mathrm{SH}$-dawn $/ B_{y}<0$ (dark; 20 August 1998) case illustrated in Fig. 27 except for the reduced ion drift in the BPS/C2 regime which is not seen in the 20 August 1998 case. The combination of very fast antisunward flow and sunlit ionosphere in this case is expected to give rise to very strong ionospheric Hall currents and a correspondingly large ground magnetic deflection (Svalgaard-Mansurov effect).

This example (Fig. 25) also illustrates the presence of the dense polar rain with the "solar wind strahl" component as expected in the $\mathrm{SH}$-dawn $/ B_{y}<0$ case. 


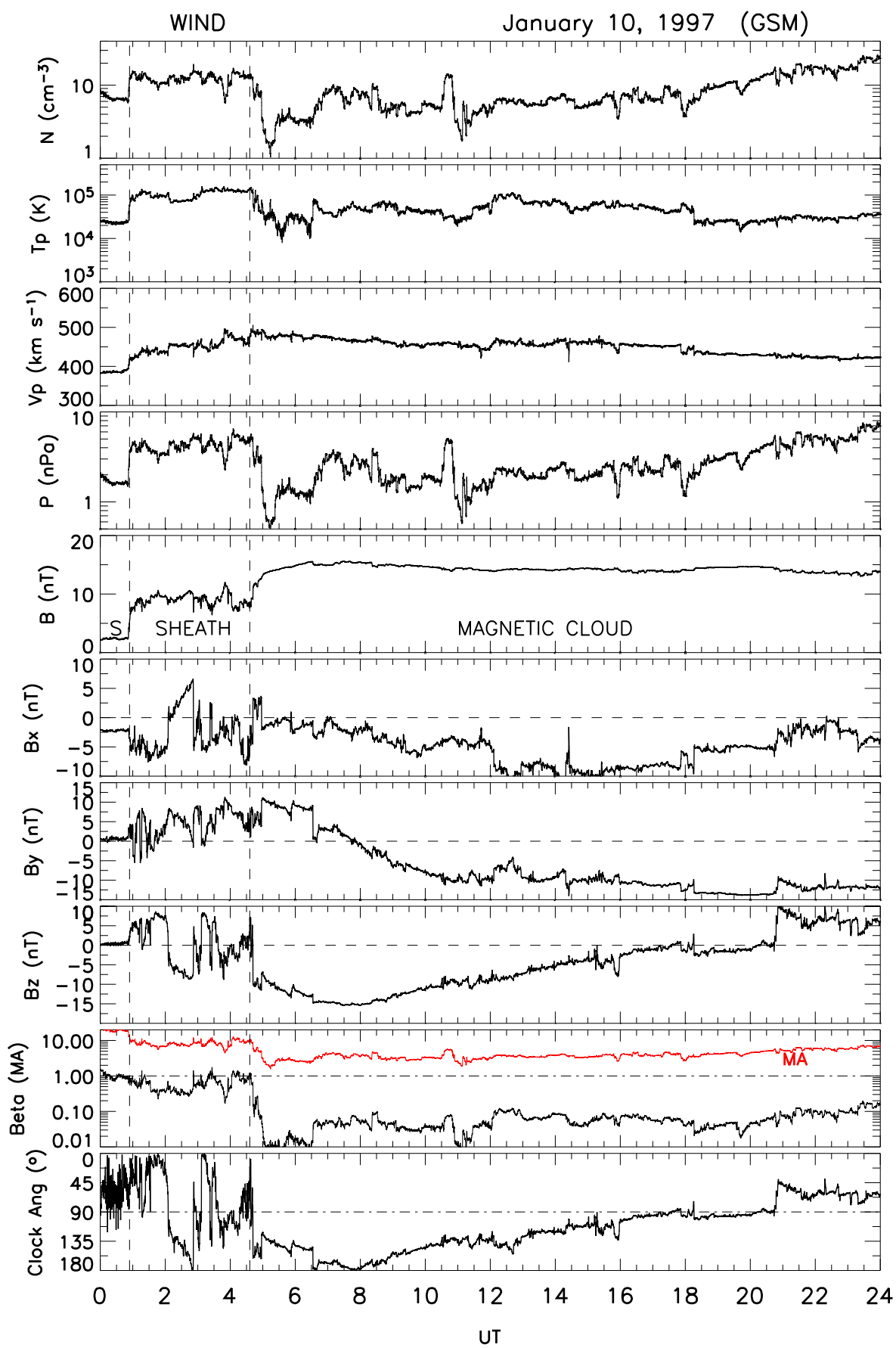

Fig. 23. Solar wind plasma and IMF data for 10 January 1997 obtained from spacecraft Wind. Same format as in Fig. 4.

The latitude profiles of Birkeland currents, ionospheric conductivity, and E-field/ion drift in our dusk-side cases (the arc-FC 2 boundary) are as schematically illustrated in Fig. 6.12 in Paschmann et al. (2002). In the latter model, applicable to nightside (21:00 MLT) cases, the E-field is (i) depressed inside the arc (regime of outward-directed Birkeland current), (ii) abruptly enhanced at the arc equatorward boundary and (iii) falls off smoothly with increasing distance equatorward of the arc. In our dusk cases a similar profile is seen inside the arc and at its poleward (polar cap) side. Feature (i), characteristic of the polarization arcs, is generally not observed at the dawn side polar cap boundary (where $\mathrm{C} 2 / \mathrm{R} 1$ is directed into the ionosphere). However, in the case of intense BPS precipitation at dawn, the field depression is observed also there, even when photo-ionization is present (see Fig. 25). This may be explained in terms of the particle 


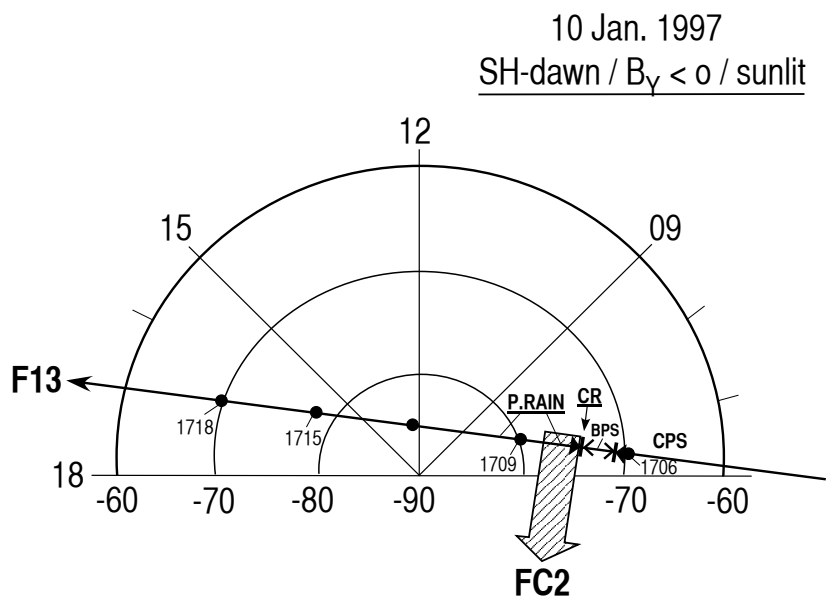

Fig. 24. DMSP F13 track across the polar cap in the Southern Hemisphere. The event gategory is: $\mathrm{SH}-\mathrm{dawn} / B_{y}<0$ (sunlit).

precipitation-induced conductivity gradient at the BPS-polar rain precipitation boundary.

Features (ii) and (iii), which are so characteristic of FC 2, have been attributed to local ionospheric modification, i.e., extraction of electrons and ions from the local ionosphere (see Paschmann et al., 2002) at the interface between the inward-directed Birkeland current and the continuing Pedersen current. The reduced Pedersen conductivity in the region of plasma depletion gives rise to enhanced $\mathbf{E}$-field in a nonlinear process. We note, however, that one part of this argumentation, i.e., ionospheric plasma depletion by electron escape in the region of inward-directed Birkeland current, does not apply to FC 2 at dawn since it is located in the regime of outward-directed Birkeland current (C1). Thus, while the FC 2/dusk case can be explained in terms of this traditional model, the FC 2/dawn case, characterized by the abrupt ion drift/E-field enhancement in the regime of outward-directed Birkeland current/polar rain precipitation at the boundary of the polar cap, is slightly different. The observations show that the drop in ionospheric conductivity at the polar cap boundary is compensated by an enhanced $\mathbf{E}$-field also in this case. For recent advances on flow channel excitation in the vicinity of dayside Birkeland current arcs we refer to Moen et al. (2008).

\section{Summary and conclusions}

We reported different representative examples illustrating the variants of a newly-discovered convection channel (our FC 2) which for a given IMF $B_{y}$ polarity appear on the dawn and dusk sides of the polar cap, in the opposite hemispheres, during intervals of nonzero IMF $B_{y}$ component. The different flow channel variants are sorted by IMF $B_{y}$ polarity, hemisphere, and dawn or dusk side of the polar cap: (i) $\mathrm{NH}$ dusk $/ B_{y}<0$, (ii) SH-dusk $/ B_{y}>0$, (iii) $\mathrm{NH}$-dawn $/ B_{y}>0$, and (iv) SH-dawn $/ B_{y}<0$. The convection channel appears as a few hundred $\mathrm{km}$ wide streak of enhanced $(\sim 1.5-3 \mathrm{~km} / \mathrm{s})$ antisunward convection at the polar cap boundary in the $\sim 06: 00$ 09:00 and 15:00-18:00 MLT sectors. The FC 2 channel is associated with mantle and polar rain precipitations. The latter is particularly prominent in the case of the dawn-side events. In the NH-dawn $/ B_{y}>0$ and SH-dawn $/ B_{y}<0$ cases the polar rain contains the "solar wind strahl" component since this is the hemisphere/ $B_{y}$ polarity combination favouring direct entry of the "strahl" in a solar wind with Parker spiral oriented IMF (opposite $B_{x}$ and $B_{y}$ polarities) (Fairfield and Scudder, 1985; Gussenhoven, 1989). The data material of this study includes five intervals of IP magnetic cloud passage at Earth (10 January 1997; 20 August 1998; 17 April 1999; 12 December 1999; 1 October 2002).

Flow channel FC 2 maximizes at the interface between the pair of outward and inward-directed Birkeland currents we refer to as $\mathrm{C} 1 / \mathrm{C} 2$. $\mathrm{C} 1$ is a current which is distributed over a wide latitude range in the polar cap where polar rain precipitation is observed. At high altitudes $\mathrm{C} 1$ connects to the magnetopause current $\left(j_{\|}(\mathrm{C} 1)=-\nabla \cdot \boldsymbol{J}_{\mathbf{M P}}\right)$. C2 is the Birkeland current at the polar cap boundary (in the $\sim 06: 00-09: 00$ or 15:00-18:00 MLT sector, depending on $B_{y}$ polarity) flowing adjacent to and in the same direction as the R1 current in the restricted latitude range of the BPS/LLBL-type precipitation (Watanabe et al., 1996) (see their Fig. 7), on the poleward side of the convection reversal (CR). The R1 current is flowing on the equatorward side of the $\mathrm{CR}$. This bifurcation of the $\mathrm{R} 1 / \mathrm{C} 2$ current in relation to the $\mathrm{CR}$ confirms a previous observation from mid-altitudes by spacecraft Polar (Farrugia et al., 2003). FC 2 is then a result of the ionospheric Pedersen current closure of the $\mathrm{C} 1 / \mathrm{C} 2$ currents.

The possible coupling of the $\mathrm{C} 1-\mathrm{C} 2-\boldsymbol{J}_{P}$ currents to dynamo action in the LLBL $\left(\boldsymbol{J}_{\mathrm{LL}}\right)$ and HBL $\left(\boldsymbol{J}_{\mathrm{MP}}\right)$ sections of the outer magnetosphere and magnetopause is shown schematically in Fig. 28. This is an illustration of momentum transfer from the solar wind along "on old open field lines" (OOFLs; polar rain electron precipitation) via dynamo action in the HBL-LLBL system. The E-field coupling from the magnetosheath ( $\left.\boldsymbol{E}_{\mathrm{MSH}}\right)$ to magnetosphere ( $\left.\boldsymbol{E}_{\mathrm{MSP}}\right)$, imposed by the magnetosheath flow, is indicated. The latter is the traditional coupling (Cowley, 1981) accounting for the traditional dawn-dusk convection convection asymmetry (Mozer et al., 1974). The $\mathrm{C} 1 / \mathrm{C} 2$ currents and their ionospheric Pedersen current closure $\left(\boldsymbol{J}_{P}\right)$ represent an important additional element to the traditional description which, in our view, is essental for the explanation of the FC 2 flow channel. C2 is the fraction of the R1/C2 current which is connected to $\mathrm{C} 1$ via ionospheric Pedersen current in the polar cap. At high altitudes the $\mathrm{C} 2$ and $\mathrm{R} 1$ currents connect to the outer and inner sections of the LLBL, respectively $\left(j_{\|}(\mathrm{R} 1 / \mathrm{C} 2)=-\nabla \cdot \boldsymbol{J}_{\mathbf{L L}}\right)$. The latter distinction is illustrated in Fig. 28. This combined LLBL-HBL model for the $\mathrm{C} 1 / \mathrm{C} 2$ currents may be considered as an extension of the model of Siscoe et al. (1991) to cases with nonzero IMF $B_{y}$ component (see also Watanabe et al., 1996 and Sonnerup and Siebert, 2003). 


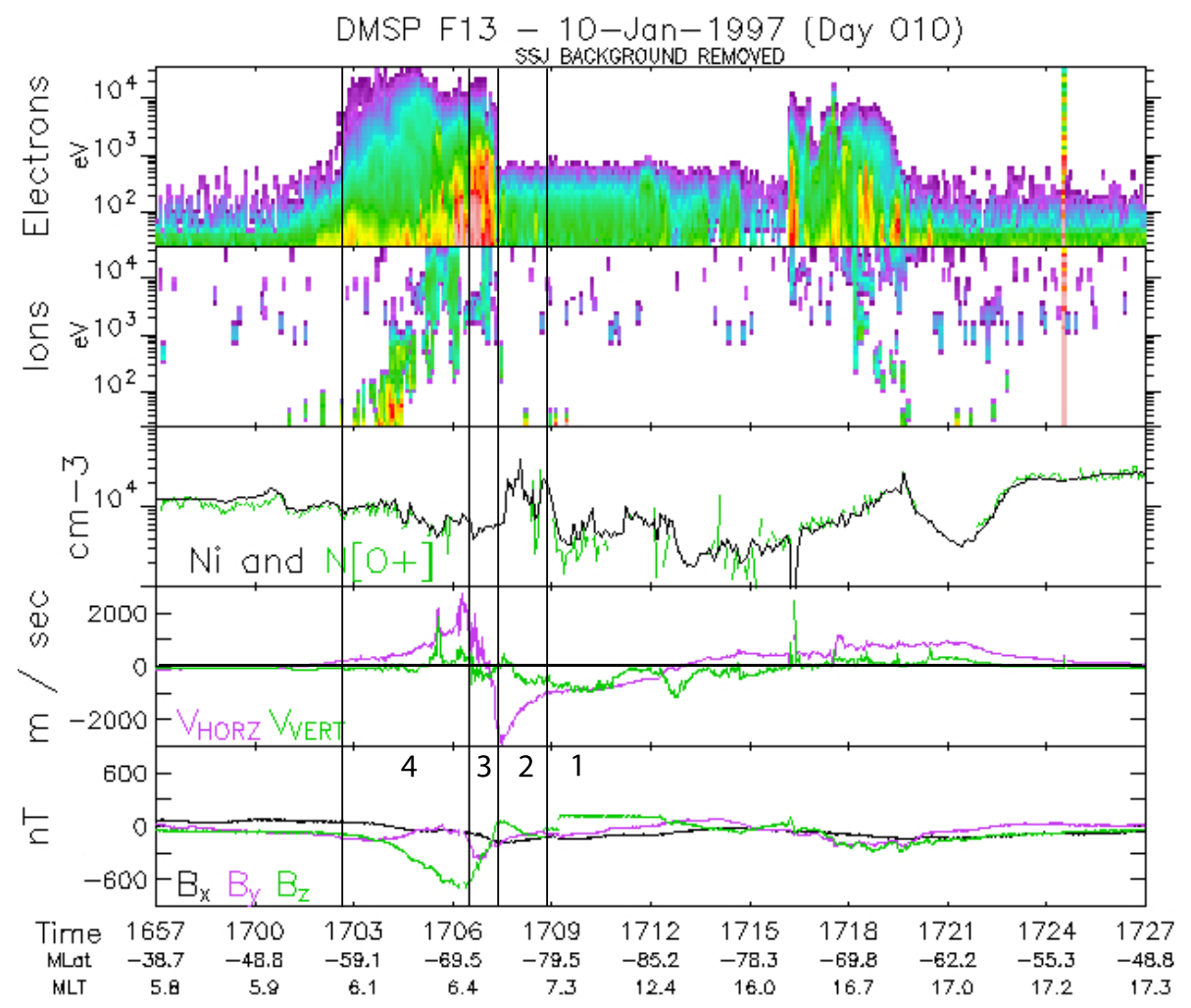

Fig. 25. Southern Hemisphere DMSP F13 data for the interval 16:57-17:27 UT. Precipitation/Birkeland current regimes marked in the figure are: (1): P.RAIN (central polar cap); (2): P.RAIN and C1 current and flow channel FC 2; (3): BPS and C2/R1 current; (4): CPS and R2 current. Event category: SH-dawn $/ B_{y}<0$.

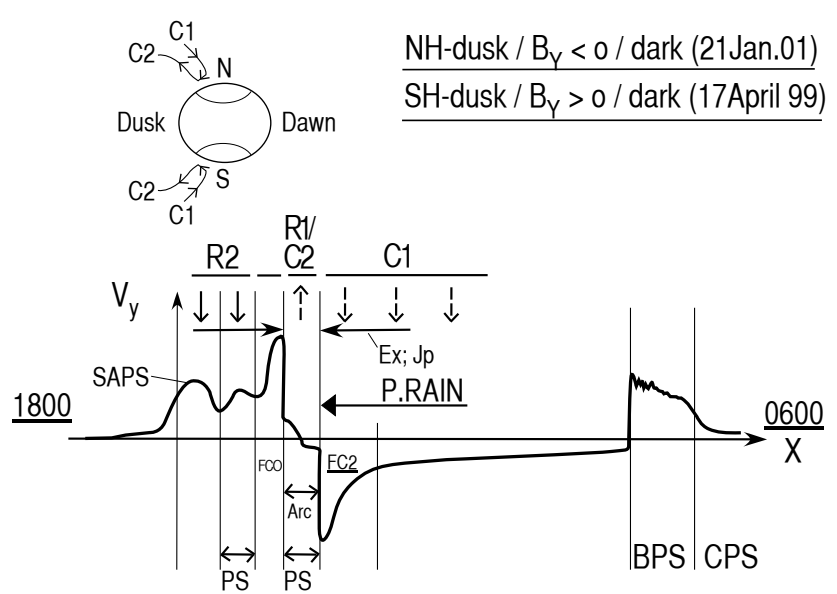

Fig. 26. Schematic illustration of DMSP F13 cross-track (horizontal component) ion drift profile $\left(V_{y}\right)$ along the dusk-dawn meridian in the context of particle precipitation and Birkeland current regimes (vertical guidelines) for event categories $\mathrm{NH}-\mathrm{dusk} / B_{y}<0$ and SH-dusk/ $B_{y}>0$. Not to scale.

The flow channel (FC 2) we reported contributes strongly (note the strength of its flows) to the IMF $B_{y}$ related dawndusk asymmetry of plasma convection and the associated

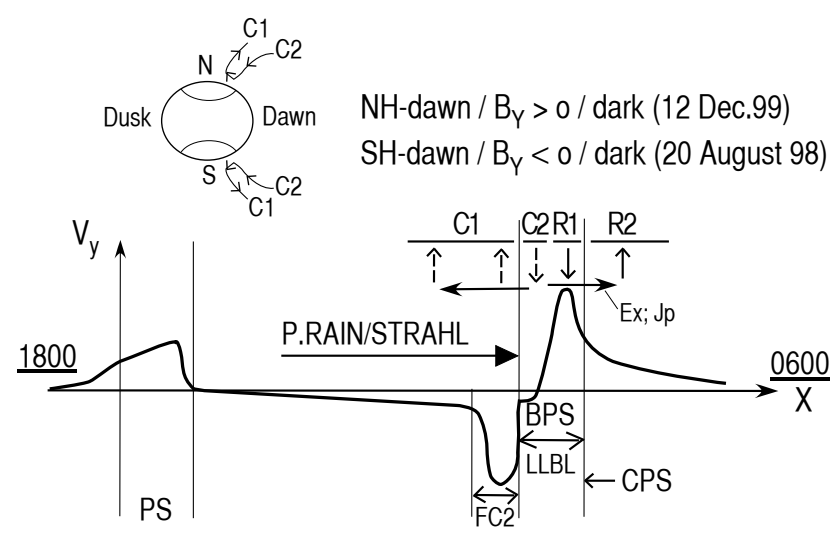

Fig. 27. Schematic illustration of DMSP F13 cross-track ion drift profile along the dusk-dawn meridian in the context of particle precipitation (PS, P.RAIN) and Birkeland current regimes (C1, C2, R1, R2) for event categories NH-dawn $/ B_{y}>0$ and SH-dawn $/ B_{y}>0$. Not to scale.

Svalgaard-Mansurov (S-M) effect. The S-M effect will be particularly strong when the flow channel FC 2 is excited in a sunlit ionosphere (with photo-ionization), as in the $10 \mathrm{Jan}-$ uary 1997 case (SH-dawn/ $B_{y}<0 /$ sunlit) shown in Fig. 25. 

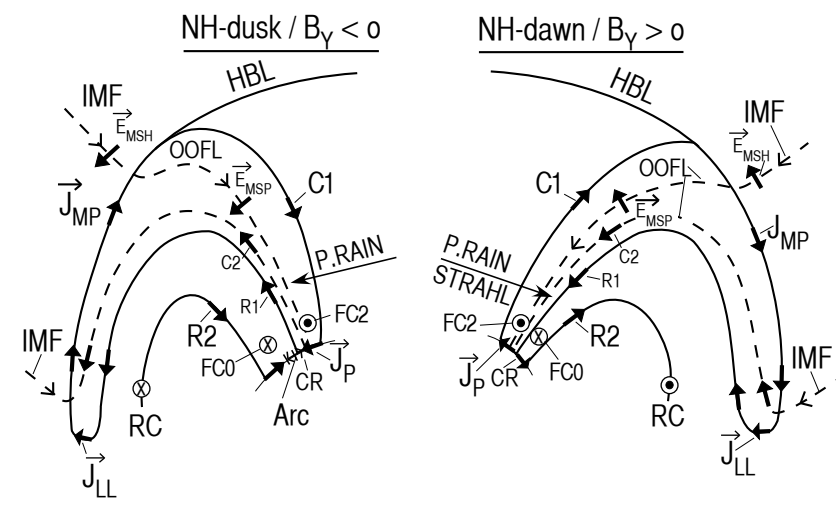

Fig. 28. Schematic illustration of flow channel FC 2, ionospheric Pedersen current $\left(\boldsymbol{J}_{P}\right)$, Birkeland currents $\mathrm{C} 1, \mathrm{C} 2, \mathrm{R} 1, \mathrm{R} 2$, polar rain (P.RAIN) precipitation (with and without the "strahl" component) and the outer magnetosphere with LLBL current $\left(\boldsymbol{J}_{\mathrm{LL}}\right)$, high-latitude boundary layer (HBL), and the magnetopause current $\left(\boldsymbol{J}_{\mathrm{MP}}\right)$ in the Northern Hemisphere $(\mathrm{NH})$. Currents and $\mathbf{E}$-fields are marked by bold arrows. The NH-dusk $/ B_{y}<0$ and NH-dawn $/ B_{y}>0$ cases are shown in the left and right sections, respectively. The IMF, "old open magnetic field lines" (OOFL) and the E-field coupling from the magnetosheath $\left(\boldsymbol{E}_{\mathrm{MSH}}\right)$ to the magnetosphere ( $\left.\boldsymbol{E}_{\mathrm{MSP}}\right)$ are also indicated. Current R2 is connected to the magnetospheric ring current (RC). Not to scale.

Acknowledgements. Access to the DMSP data base (https://swx. plh.af.mil) was kindly provided by W. F. Denig. DMSP data are from the Air Force Geophysics Research Laboratory at Hanscom, MA. SuperDARN data are obtained from http://superdarn.jhuapl. edu. Work at UNH is supported by NASA grants NNG05GG25G and NNX08AD11G as well as by NASA WIND/SWE and MFI grants.

Topical Editor I. A. Daglis thanks K. Oksavik and another anonymous referee for their help in evaluating this paper.

\section{References}

Burke, W. J., Machuzak, J. S., Maynard, N. C., Basinska, E. M., Erickson, G. M., Hoffman, R. A., Slavin, J. A., and Hanson, W. B.: Auroral ionospheric signatures of the plasma sheet boundary layer in the evening sector, J. Geophys. Res., 99, 2489-2499, 1994.

Burlaga, L. F., Sittler, E., Mariani, F., and Schwenn, R.: Magnetic loop behind an interplanetary shock: Voyager, Helios, and IMP8 observations, J. Geophys. Res., 86, 6673-6684, 1981.

Cowley, S. W. H.: Magnetospheric and ionospheric flow and the interplanetary magnetic field, in: The Physical Basis of the Ionosphere in the Solar-Terrestrial System, no. 295 in Conference Proceedings, pp. 4-1-4-12, AGARD (Advisory Group for Aerospace Research \& Development), NATO, Neuilly sur Seine, France, 1981.

Crooker, N. U. and Rich, F. J.: Lobe cell convection as a summer phenomenon, J. Geophys. Res., 98, 13403-13407, 1993.

Fairfield, D. H. and Scudder, J. D.: Polar rain: Solar coronal electrons in the Earth's magnetosphere, J. Geophys. Res., 90, 4055-
4068, 1985.

Fairfield, D. H., Wing, S., Newell, P. T., Ruohoniemi, J. M., Gosling, J. T., and Skoug, R. M.: Polar rain gradients and fieldaligned polar cap potentials, J. Geophys. Res., 113, A10203, doi:10.1029/2008JA013437, 2008.

Farrugia, C. J., Scudder, J. D., Freeman, M. P., Janoo, L., Lu, G., Quinn, J. M., Arnoldy, R. L., and Torbert, R. B.: Geoeffectiveness of three Wind magnetic clouds: A comparative study, J. Geophys. Res., 103, 17261-17278, 1998.

Farrugia, C. J., Sandholt, P. E., Maynard, N. C., Torbert, R. B., and Ober, D. M.: Temporal variations in a four-sheet fieldaligned current system and associated aurorae as observed during a Polar-ground magnetic conjunction in the midmorning sector, J. Geophys. Res., 108(A6), 1230, doi:10.1029/2002JA009619, 2003.

Farrugia, C. J., Lund, E. J., Sandholt, P. E., Wild, J. A., Cowley, S. W. H., Balogh, A., Mouikis, C., Möbius, E., Dunlop, M. W., Bosqued, J.-M., Carlson, C. W., Parks, G. K., Cerisier, J.C., Kelly, J. D., Sauvaud, J.-A., and Rème, H.: Pulsed flows at the high-altitude cusp poleward boundary, and associated ionospheric convection and particle signatures, during a Cluster FAST - SuperDARN-Søndrestrøm conjunction under a southwest IMF, Ann. Geophys., 22, 2891-2905, 2004a.

Farrugia, C. J., Sandholt, P. E., Torbert, R. B., and Østgaard, N.: Temporal and spatial aspects of the cusp inferred from local and global ground- and space-based observations in a case study, J. Geophys. Res., 109, A04209, doi:10.1029/2003JA010121, 2004b.

Foster, J. C. and Vo, H. B.: Average characteristics and activity dependence of the subauroral polarization stream, J. Geophys. Res., 107(A12) ,1475, doi:10.1029/2002JA009409, 2002.

Gosling, J. T., Thomsen, M. F., Bame, S. J., Elphic, R. C., and Russell, C. T.: Plasma flow reversals at the dayside magnetopause and the origin of asymmetric polar cap convection, J. Geophys. Res., 95, 8073-8084, 1990.

Greenwald, R. A., Baker, K., Dudeney, J. R., Pinnock, M., Thomas, E. C., Villain, J. P., Cerisier, J.-C., Senior, C., Hanuise, C., Hunsucker, R. D., Sofko, G. J., Koehler, J., Nielsen, E., Pellinen, R., Walker, A. D. M., Sato, N., and Yamagishi, H.: DARN/SUPERDARN: A Global View of the Dynamics of HighLatitude Convection, Space Sci. Rev., 71, 761-796, 1995.

Gussenhoven, M. S.: Polar rain and the question of direct particle access, in: Electromagnetic Coupling in the Polar Clefts and Caps, edited by: Sandholt, P. E. and Egeland, A., vol. 278 of NATO ASI Series, pp. 43-60, Kluwer Academic Publishers, Dordrecht, Holland, 1989.

Jørgensen, T. S., Friis-Christensen, E., and Wilhjelm, J.: Interplanetary magnetic field direction and high-latitude ionospheric currents, J. Geophys. Res., 77, 1976-1977, 1972.

Karlsson, T. and Marklund, G. T.: A statistical study of intense lowaltitude electric fields observed by Freja, Geophys. Res. Lett., 23, 1005-1008, 1996.

Kullen, A., Buchert, S., Karlsson, T., Johansson, T., Lileo, S., Eriksson, A., Nilsson, H., Marchaudon, A., and Fazakerley, A. N.: Plasma transport along discrete auroral arcs and its contribution to the ionospheric plasma convection, Ann. Geophys., 26, 32793293, 2008, http://www.ann-geophys.net/26/3279/2008/.

Lepping, R. P., Berdichevsky, D. B., and Wu, C.-C.: Sun-Earth elec- 
trodynamics: The solar wind connection, Recent Res. Devel. Astrophys., 1, 139-171, 2003.

Lockwood, M., Cowley, S. W. H., and Freeman, M. P.: The excitation of plasma convection in the high-latitude ionosphere, J. Geophys. Res., 95, 7961-7972, 1990.

Lockwood, M., Denig, W. F., Farmer, A. D., Davda, V. N., Cowley, S. W. H., and Luhr, H.: Ionospheric signatures of pulsed reconnection at the Earth's magnetopause, Nature, 361, 424-428, 1993.

Lu, G., Richmond, A., Emery, B., Reiff, P., de la Beaujardiére, O., Rich, F., Denig, W., Kroehl, H., Lyons, L., Ruohniemi, J., Friis-Christensen, E., Opgenoorth, H., Persson, M., Lepping, R., Rodger, A., Hughes, T., McEwin, A., Dennis, S., Morris, R., Burns, G., and Tomlinson, L.: Interhemispheric asymmetry of the high-latitude ionospheric convection pattern, J. Geophys. Res., 99, 6491-6510, 1994.

Lund, E. J., Farrugia, C. J., and Sandholt, P. E.: Momentum transfer at the high-latitude magnetopause and boundary layers, Ann. Geophys., 26, 2449-2458, 2008, http://www.ann-geophys.net/26/2449/2008/.

Marklund, G.: Auroral arc classification scheme based on the observed arc-associated electric field pattern, Planet. Space Sci., 32, 193-211, 1984.

Meng, C.-I., Akasofu, S.-I., and Anderson, K. A.: Dawn-dusk gradient of the precipitation of low-energy electrons over the polar cap and its relation to the interplanetary magnetic field, J. Geophys. Res., 82, 5271-5275, 1977.

Moen, J., Rinne, Y., Carlson, H. C., Oksavik, K., Fujii, R., and Opgenoorth, H.: On the relationship between thin birkeland current arcs and reversed flow channels in the winter cusp/cleft, J. Geophys. Res., 113, A09220, doi:10.1029/2008JA013061, 2008.

Mozer, F. S., Gonzalez, W. D., Bogott, F., Kelley, M. C., and Schutz, S.: High-latitude electric fields and the three-dimensional interaction between the interplanetary and terrestrial magnetic fields, J. Geophys. Res., 79, 56-63, 1974.

Oksavik, K., Moen, J., and Carlson, H. C.: High-resolution observations of the small-scale flow pattern associated with a poleward moving auroral form in the cusp, Geophys. Res. Lett., 31, L11807, doi:10.1029/2004GL019838, 2004.

Paschmann, G., Haaland, S., and Treumann, R. (Eds.): Auroral Plasma Physics, Kluwer Academic Publishers, Dordrecht, Holland, 2002.

Reiff, P. H., Burch, J. L., and Heelis, R. A.: Dayside auroral arcs and convection, Geophys. Res. Lett., 5, 391-394, 1978.

Rinne, Y., Moen, J., Oksavik, K., and Carlson, H. C.: Reversed flow events in the winter cusp ionosphere observed by the European Incoherent Scatter (EISCAT) Svalbard Radar, J. Geophys. Res., 112, A10313, doi:10.1029/2007JA012366, 2007.

Ruohoniemi, J. M. and Greenwald, R. A.: Dependencies of high-latitude plasma convection: Consideration of interplanetary magnetic field, season, and universal time factors in statistical patterns, J. Geophys. Res., 110, A09204, doi:10.1029/2004JA010815, 2005.

Russell, C. T. and Elphic, R. C.: Initial ISEE magnetometer results: Magnetopause observations, Space Sci. Rev., 22, 681-715, 1978.

Sandholt, P. E. and Farrugia, C. J.: Poleward moving auroral forms (PMAFs) revisited: responses of aurorae, plasma convection and Birkeland currents in the pre- and postnoon sectors under positive and negative IMF By conditions, Ann. Geophys., 25, 1629_
$1652,2007 a$.

Sandholt, P. E. and Farrugia, C. J.: The role of poleward moving auroral forms in the dawn-dusk precipitation asymmetries induced by IMF $B_{y}$, J. Geophys. Res., 112, A04203, doi:10.1029/2006JA011952, 2007b.

Sandholt, P. E. and Newell, P. T.: Ground and satellite observations of an auroral event at the cusp/cleft equatorward boundary, J. Geophys. Res., 97, 8685-8691, 1992.

Sandholt, P. E., Lockwood, M., Oguti, T., Cowley, S. W. H., Freeman, K. S. C., Lybekk, B., Egeland, A., and Willis, D. M.: Midday auroral breakup events and related energy and momentum transfer from the magnetosheath, J. Geophys. Res., 95, 10391060, 1990.

Sandholt, P. E., Farrugia, C. J., and Denig, W. F.: Detailed dayside auroral morphology as a function of local time for southeast IMF orientation: implications for solar wind-magnetosphere coupling, Ann. Geophys., 22, 3537-3560, 2004, http://www.ann-geophys.net/22/3537/2004/.

Sandholt, P. E., Dyrland, M., and Farrugia, C. J.: Dayside aurorae and polar arcs under south-east IMF orientation, Ann. Geophys., 24, 3421-3432, 2006a.

Sandholt, P. E., Farrugia, C. J., Lund, E. J., and Denig, W. F.: IMF $B_{y}$ and the Spatio-Temporal Structure of the Dayside Aurora, in: Recurrent Magnetic Storms: Corotating Solar Wind Streams, edited by: Tsurutani, B. T., vol. 167 of Geophysical Monograph Series, pp. 213-233, American Geophysical Union, 2006b.

Siscoe, G. L., Lotko, W., and Sonnerup, B. U. O.: A high-latitude, low-latitude boundary layer model of the convection current system, J. Geophys. Res., 96, 3487-3495, 1991.

Siscoe, G. L., Erickson, G. M., Sonnerup, B. U. O., Maynard, N. C., Siebert, K. D., Weimer, D. R., and White, W. W.: Deflected magnetosheath flow at the high-latitude magnetopause, J. Geophys. Res., 105, 12851-12858, 2000.

Smiddy, M., Burke, W. J., Kelley, M. C., Saflekos, N. A., Gussenhoven, M. S., Hardy, D. A., and Rich, F. J.: Effects of highlatitude conductivity on observed convection electric fields and Birkeland currents, J. Geophys. Res., 85, 6811-6818, 1980.

Smith, M. F.: Transient dayside reconnection and its effect on the ionosphere, in: Physical Signatures of Magnetospheric Boundary Layer Processes, edited by: Holtet, J. A. and Egeland, A., vol. 425 of NATO ASI Series, pp. 275-289, Kluwer Academic Publishers, Dordrecht, Holland, 1994.

Sonnerup, B. U. O. and Siebert, K. D.: Theory of the low-latitude boundary layer and its coupling to the ionosphere: A tutorial review, in: Earth's Low-Latitude Boundary Layer, edited by: Newell, P. T. and Onsager, T., vol. 133 of Geophysical Monograph, pp. 13-32, American Geophysical Union, Washington, D.C., 2003.

Southwood, D. J.: The ionospheric signature of flux transfer events, J. Geophys. Res., 92, 3207-3213, 1987.

Stern, D. P.: Magnetospheric dynamo processes, in: Magnetospheric Currents, edited by: Potemra, T. A., vol. 28 of Geophys. Monogr., pp. 200-207, AGU, Washington, D.C., 1984.

Taguchi, S., Sugiura, M., Winningham, J. D., and Slavin, J.: Characterization of the IMF $B_{y}$-dependent field-aligned currents in the cleft region based on DE 2 observations, J. Geophys. Res., 98, 1393-1407, 1993.

Tanaka, T.: Interplanetary magnetic field $B_{y}$ and auroral conductance effects on high-latitude ionospheric convection patterns, J. 
Geophys. Res., 106, 24505-24516, 2001.

Watanabe, M., Iijima, T., and Rich, F. J.: Synthesis models of dayside field-aligned currents for strong interplanetary magnetic field $B_{y}$, J. Geophys. Res., 101, 13303-13319, 1996.
Weimer, D. R.: Models of high-latitude electric potentials derived with a least error fit of spherical harmonic coefficients, J. Geophys. Res., 100, 19595-19608, 1995. 